\title{
生长素代谢与信号转导及其调控种子休眠与萌发的 分子机制
}

宋松泉 ${ }^{1,2^{*}}$, 刘 $^{2}{ }^{2}$, 唐翠芳 ${ }^{3}, 弓$ 文虎 $^{2}$, 徐恒恒 $^{2}$, 张琪 $^{2}$, 高家东 $^{2}$

1. 中国科学院植物研究所, 北京 100093 ;

2. 广东省农作物种质资源保存与利用重点实验室/广东省农业科学院农业生物基因研究中心, 广州 510640;

3. 深圳前海国旺大地基金管理有限公司, 广州 510630

* 联系人, E-mail: sqsong@ibcas.ac.cn

2020-04-30 收稿, 2020-06-12 修回, 2020-06-12 接受, 2020-06-15 网络版发表

国家科技支撑计划(2012BAC01B05)、广东省农作物种质资源保存与利用重点实验室项目(2020B121201008)和国家自然科学基金(31871716) 资助

摘要 种子萌发是一个由遗传和环境因子共同调控的复杂过程, 其中植物激素调节可能是种子植物萌发过程中的 一种高度保守的机制. 生长素是植物中的一种最重要的信号分子, 调控植物生长发育的各个方面, 包括形态发生和 对环境变化的响应等. 生长素通过多条平行的途径被生物合成和失活, 也通过典型和非典型途径被感受和转导. 生 长素在种子休眠和萌发中的作用主要受其生物合成与分解代谢以及信号转导途径的调控. 本文主要综述了生长素 的生物合成与代谢、生长素的信号转导以及它们对种子休眠与萌发的调控的研究进展。此外, 我们也提出了在本 领域需要进一步研究的科学问题, 试图为解释生长素调控种子休眠与萌发的分子机理提供参考.

关键词 生长素, 休眠, 萌发, 代谢, 种子, 信号转导

萌发是将静止的种子转化为具有高代谢活性的幼 苗, 是种子植物生命周期中的关键步骤, 是植物进人生 态系统以及在适宜的条件下生长与繁育的前提. 在农 业生产中，迅速一致的种子萌发是作物高产优质的必 要条件. 种子通过后熟(干藏)或者在物种专一的温度下 吸胀(层积)解除休眠并促进萌发. 种子萌发是一个复杂 的多步骤过程, 在这个过程中静止的干燥种子迅速恢 复其代谢活性, 完成胚伸出周围结构的细胞事件, 为随 后的幼苗生长做准备 ${ }^{[1,2]}$.

种子萌发由遗传和环境因素共同决定，其中休眠 释放与萌发的激素调控可能是种子植物中的一种高度 保守的机制 ${ }^{[2,3]}$. 研究表明, 脱落酸 (abscisic acid, ABA) 和赤需素 (gibberellin, GA) 在种子萌发中起重要作
用 ${ }^{[4,5]}$. 外源 $\mathrm{ABA}$ 抑制种子萌发, $\mathrm{ABA}$ 生物合成或者信 号转导缺失的突变体增加种子的萌发率, 脱落酸不敏 感因子(abscisic acid insensitive, ABI)ABI1、ABI2、 ABI3、ABI4和ABI5对种子萌发有抑制作用 ${ }^{[6-8]}$. 相反, 外源 $\mathrm{GA}$ 促进种子萌发. GA 突变体, 如 $g a 1$ 和 $g a 2$ 表现出 种子萌发延迟或者缺陷, GA信号转导必需的DELLA (Asp-Glu-Leu-Leu-Ala)蛋白RGA(repressor of GA)、 GAI(gibberellic acid insensitive)和RGL2(RGA-like 2)在 种子萌发中起负调控作用 ${ }^{[9 \sim 11]}$. 除ABA和GA外, 植物激 素生长素(auxin) ${ }^{[12,13]}$ 、乙烯(ethylene $)^{[14,15]}$ 和细胞分裂 素(cytokinin $)^{[16]}$ 也在种子休眠释放和萌发中起重要 作用.

生长素是植物中的一种重要的信号分子, 几乎调控 
植物生长发育的所有方面, 包括形态发生和对环境变化 的响应等. 细胞内适宜的生长素浓度促进细胞的分裂、 生长和分化, 从而影响器官的形成、生长以及最终的植 物形态 ${ }^{[17]}$. 生长素通过多条平行的途径被合成、储存 和失活 ${ }^{[18]}$, 也通过典型和非典型途径进行感受和转

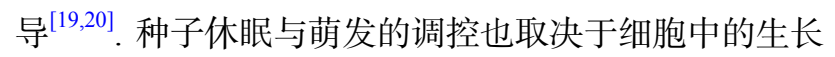
素浓度以及细胞(组织)对生长素的敏感性. 外源高浓度 的生长素 $(0.3 \sim 1 \mu \mathrm{mol} / \mathrm{L}$ 吲哚-3-乙酸(indole-3-acetic acid, IAA))抑制拟南芥(Arabidopsis thaliana) 种子的萌发 ${ }^{[21]}$, 而低浓度的生长素( $0.03 \sim 3 \mathrm{nmol} / \mathrm{L}$ IAA)促进种子萌发 和幼苗形成 ${ }^{[22]}$. 生长素反应因子(auxin response factor, ARF)10/16 通过介导 $A B I 3$ 的表达作为ABA信号途径的 正调控因子起作用, arf10 arf16双突变体表现出种子萌 发对ABA不敏感 ${ }^{[12]}$. 表达 $m A R F 10$ (miR160-resistant form of ARF10)的转基因种子对外源 $\mathrm{ABA}$ 的萌发抑制过敏 感, 而 $m i R 160$ 的异位表达导致其对ABA的敏感性降 低 ${ }^{[21]}$. 转录组研究表明, 在 $g a 1$ 突变体种子中, $\mathrm{GA}_{4}$ 处理 显著上调生长素运输载体基因 $A U X 1$ ( $A U X I N$ RESISTANT 1)、PIN2(PIN-FORMED 2)和PIN7的表达 ${ }^{[23]}$. AUX1是ABA抑制种子萌发所必需的, 其功能缺失突变 体表现出对ABA的抗性增加 ${ }^{[24]}$. 此外, 与休眠种子比较, 后熟种子中生长素输出和输人运输载体都被上调表 达 $^{[25]}$, 表明生长素运输载体也在种子萌发中起作用. 这 些结果表明, 不同的生长素信号转导途径通过影响 $\mathrm{ABA}$ 和/或GA信号转导途径参与种子萌发. 近几年来, 生长素的生物合成与代谢, 尤其是生长素信号转导途

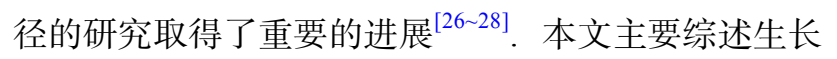
素的生物合成与分解代谢、生长素的信号转导, 以及 它们对种子休眠与萌发调控的研究进展. 此外, 我们也 提出了在本领域需要进一步研究的科学问题, 试图为解 释生长素调控种子休眠与萌发的分子机理提供参考.

\section{1 生长素的生物合成和分解代谢}

\section{1 生长素的生物合成}

IAA是植物中最丰富的内源生长素, 通过多条平行 的途径被生物合成(图1) ${ }^{[17,18]}$. 尽管植物中还存在其他 的内源生长素, 如4-Cl-IAA(4-chloro-IAA)和苯乙酸 (phenylacetic acid, PAA)等, 但它们在植物物种中的分 布不普遍, 且具有非常弱的生长素效应 ${ }^{[29]}$. 研究发现, 色氨酸(tryptophan, Trp)是植物和细菌中IAA合成的共 同前体 ${ }^{[18]}$. 在植物中, $T r p$ 是在叶绿体中由莽草酸途径 (shikimate pathway)的最终产物分支酸(chorismate)产生 的 ${ }^{[30]}$. 拟南芥色氨酸氨基转移酶(tryptophan aminotransferase, TAA)和YUCCA(YUC)黄素单加氧酶家族(flavin-containing monooxygenase family)由Trp通过吼梠3-丙酮酸(indole-3-pyruvate，IPA)产生IAA(图1) ${ }^{[18,31,32]}$. 遗传和生物化学研究表明, $T A A$ 和 $Y U C$ 家族在不同植物 的IAA生物合成中起关键作用, 包括拟南芥、玉米 $(Z e a$ mays)、水稻(Oryza sativa) 和地钱(Marchantia polymor$p h a)^{[33-35]}$. 此外, 在拟南芥IAA和吲哚硫代葡萄糖苷(indole glucosinolate, IG)生物合成的最初步骤中, Cyt P450单加氧酶(cytochrome P450 monooxygenase) CYP79B2 和CYP79B3催化 Trp转化成为吲哚-3-乙醛肜 (indole-3-acetaldoxime, IAOx), 但随后产生IAA的途径 仍然不够清楚(图1) ${ }^{[18,36]}$. 吲哚-3-乙酰胺(indole-3-acetaldoxime，IAM)、吲哚-3-乙醛(indole-3-acetaldehyde, IAAld)和色胺(tryptamine, TAM)也被认为是从 $\operatorname{Trp}$ 产生 IAA的前体, 但与这些中间产物生物合成有关的途径也 不清楚(图1) ${ }^{[18,34,37]}$.

\subsubsection{IPA途径合成IAA}

在植物中, 评价IAA生物合成途径的关键标准包 括:（1）基因鉴定; (2) 酶活性测定; (3) 代谢产物定量; (4) 生理作用分析; (5) 在植物物种中的分布(表1 $)^{[18]}$. 根 据这些标准, IPA途径是植物中第一个完整的和普遍保

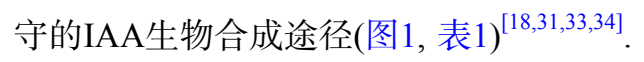

在拟南芥中, TAA1由 $S A V 3 / W E I 8 / T I R 2$ (SHADE AVOIDANCE 3/WEAK ETHYLENE INSENSITIVE 8/ TRANSPORT INHIBITOR RESPONSE 2)基因编码, 在 IPA途径的第一步起作用 ${ }^{[38,39]}$. 体外重组的TAA1蛋白 催化Trp转化成为IPA ${ }^{[38]}$. 拟南芥中, TAR1(TAA1-related 1 )和TAR2 作为 $T r p$ 氨基转移酶具有冗余作用 ${ }^{[38]}$. 在 $T A A$ 家族缺失的拟南芥突变体中, 内源IAA和IPA的含量减 少 ${ }^{[31,32]}$; 相反, TAAl的表达增加, 内源IPA的水平升 高 $^{[31]}$. TAA1和TAR基因的多重突变在不同的生物学过 程中引起严重的生长素缺陷表型, 包括胚胎发生、花 发育、幼苗生长、维管模式、侧根形成、向性、避荫 和温度依赖的下胚轴伸长等 ${ }^{[38,39]}$, 表明 $T A A$ 家族在植物 的生长和发育中起重要作用. $T A A$ 基因家族的直系同源 基因广泛分布于维管和非维管植物中, 表明 $T A A$ 基因在 植物界的进化中是高度保守的(表1 $)^{[18,35]}$. 例如, $V T 2$ (VANISHING TASSEL 2)和FIB(FISH BONE)基因分别 是玉米和水稻中 $T A A$ 家族的共直系同源基因(co-ortho$\log$ ), 这些基因的突变导致IAA水平降低, 引起多效性 


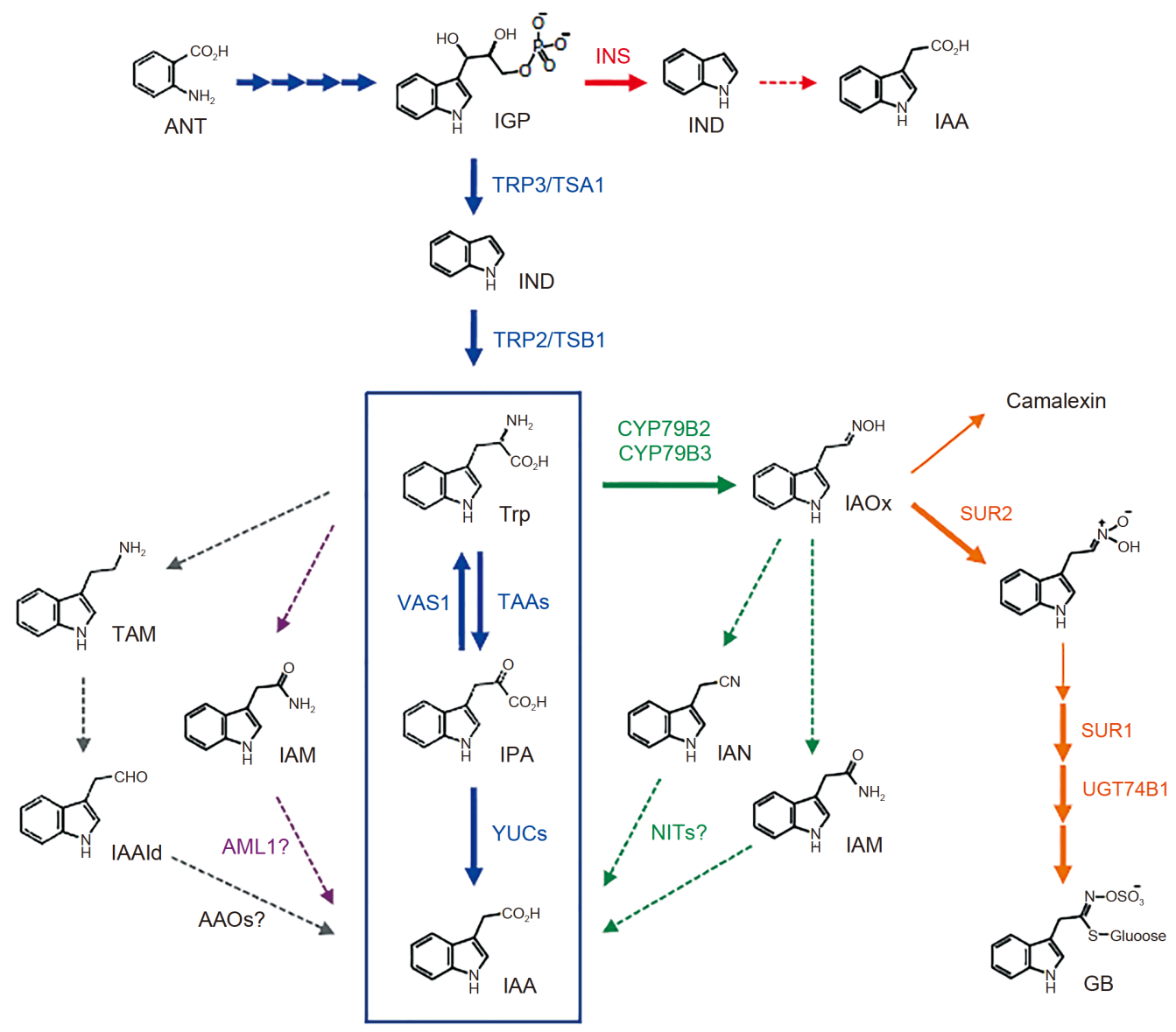

图 1 拟南芥IAA生物合成途径和次生代谢途径的图解模型 ${ }^{[18]}$ ，常见的色氨酸生物合成途径和弜哚-3-丙酮酸途径用蓝色表示，拟南芥中的吲 哚-3-乙醛肜途径用绿色表示, 㖿哚-3-乙酰胺途径用紫色表示, 色胺途径用灰色表示, Trp不依赖的途径用红色表示, 拟南芥中的次生代谢途径 用棕色表示. 陆生植物中高度保守的IPA途径用方框围住. 已鉴定的酶反应步骤用粗体字表示. 有待证实的酶反应步骤用虚线箭头表示. ANT, 氨 基苯甲酸; GB, 芸莒葡糖硫苷; IAA, 吲哚-3-乙酸; IAAld, 吲哚-3-乙醛; IAN, 吲哚-3-乙腈; IGP, 吲哚-3-甘油磷酸; IND, 吲哚; AAO, 醛氧化酶; CYP79B2/3, 细胞色素P450单氧化酶 $2 / 3$; IMI1, 酰胺酶1; INS, 吲哚合酶; NIT, 腈水解酶; SUR1/2, SUPERROOT1/2; TAA, 色氨酸氨基转移酶; TRP3/TSA1, 色氨酸合酶 $\alpha$-亚基; TRP2/TSB1, 色氨酸合酶 $\beta$-亚基; VAS1, 吡哆醛磷酸依赖的氨基转移酶1; YUC, YUCCA黄素单加氧酶 Figure 1 A schematic model of the IAA biosynthetic pathways and secondary metabolic pathways in Arabidopsis ${ }^{[18]}$. The common tryptophan biosynthesis and indole-3-pyruvate pathways are shown in blue, the indole-3-acetaldoxime pathway in Arabidopsis is shown in green, the indole-3acetamide pathway is shown in purple, the tryptamine pathway is shown in gray, the Trp-independent pathway is shown in red, and secondary metabolite pathways in Arabidopsis are shown in brown. The IPA pathway that is highly conserved in land plants is enclosed in the box. Characterized enzyme reaction steps are in bold typeface. Enzyme reaction steps remaining to be clarified are shown by dashed arrows. ANT, anthranilate; GB, glucobrassicin; IAA, indole-3-acetic acid; IAAld, indole-3-acetaldehyde; IAN, indole-3-acetonitrile; IGP, indole-3-glycerol phosphate; IND, indole; AAO, aldehyde oxidase; CYP79B2/3, cytochrome P450 monooxygenases2/3; IMI1, amidase1; INS, indole synthase; NIT, nitrilase; SUR1/2, SUPERROOT1/2; TAA, tryptophan aminotransferase; TRP3/TSA1, Trp synthase $\alpha$-subunit; TRP2/TSB1, Trp synthase $\beta$-subunit; VAS1, pyridoxal phosphate-dependent aminotransferase1; YUC, YUCCA flavin-containing monooxygenase

\section{生长素缺陷表型 ${ }^{[40]}$.}

$Y U C$ 基因编码黄素单加氧酶. YUC1功能获得突变 体(yuc1D)在光照条件下表现出高生长素表型，例如偏 上性子叶和延长的下胚轴 ${ }^{[33]}$. 研究人员在拟南芥中发 现了 11 个 $Y U C$ 基因(表1)，每个YUC基因的过表达导致 拟南芥中IAA水平的增加和高生长素表型，这表明 YUC蛋白催化IAA生物合成中的限速步骤 ${ }^{[31,41 ~ 43]}$. 重 组的YUC1蛋白最初被鉴定为催化色胺的 $N$-差基化作
用 ${ }^{[33]}$, 因此 $T A A$ 和 $Y U C$ 基因家族曾被认为定位于独立的 IAA生物合成途径中 ${ }^{[36,38]}$. 然而, 遗传和生化研究表明, 这两个基因在同一途径中顺序地起作用(图 1) ${ }^{[18,31,32]}$. 重组的YUC2蛋白以NADPH依赖的方式催化IPA转化 成为IAA ${ }^{[31]}, Y U C 4$ 和YUC6蛋白在体外能够转化IPA成 为 $\mathrm{IAA}^{[44,45]}$. $Y U C$ 基因的多重敲除突变体在各个生长发 育阶段表现出严重的生长素缺陷表型，包括胚胎发 生、花发育、幼苗生长、维管模式、侧根形成和避荫 
表 1 拟南芥中生长素生物合成途径的主要组分 ${ }^{[18] a)}$

Table 1 The main components of IAA biosynthesis pathways in Arabidopsis ${ }^{[18]}$

\begin{tabular}{|c|c|c|c|c|c|c|}
\hline 途径 & 基因 & 酶 & 底物/产物 & $\begin{array}{c}\text { 敲除突变体中催化 } \\
\text { 产物的减少 }\end{array}$ & 生理作用 & $\begin{array}{c}\text { 非维管植物中直系 } \\
\text { 同源基因 }\end{array}$ \\
\hline \multirow[t]{2}{*}{ IPA } & $T A A$ & $\begin{array}{l}\text { 色氨酸氨基 } \\
\text { 转移酶 }\end{array}$ & Trp/IPA & 是 & 是 & 是 \\
\hline & $Y U C$ & 黄素单加氧酶 & IPA/IAA & 是 & 是 & 是 \\
\hline \multirow[t]{2}{*}{ IAOx } & CYP79B & $\begin{array}{l}\text { Cyt P450 } \\
\text { 单加氧酶 }\end{array}$ & Trp/IAOx & 是 & 是 & 是 \\
\hline & $N I T$ & 腈水解酶 & IAN/IAA & - & - & - \\
\hline IAM & $A M I 1$ & 酰胺酶 & IAM/IAA & - & - & - \\
\hline TAM & $A A O$ & 醛氧化酶 & IAAld/IAA & - & - & - \\
\hline Trp-不依赖 & $I N S$ & 吲哚合酶 & IGP/IND & 是 & 是 & - \\
\hline
\end{tabular}

a) -, 没有被观察到或者没有被报道

等，表明 $Y U C$ 基因家族在植物生长发育中起关键作 用 ${ }^{[41,42,46]}$. 内源IPA水平在多重 $y u c$ 敲除突变体中增加以 及在 $Y U C$ 过表达株系中减少 ${ }^{[31]}$. 尽管一些 $y u c$ 单个敲除 突变体在某一条件下可能具有敏感的表型，但每个 $Y U C$ 基因的单个敲除突变体不表现出生长素表型的显 著减少 ${ }^{[47]}$ ，表明 $Y U C$ 基因家族的功能圥余 ${ }^{[42]}$. 此外, $Y U C$ 的直系同源基因普遍存在于维管和非维管植物中, 如水稻 ${ }^{[48]}$ 、玉米 ${ }^{[49]}$ 和苔类植物地钱 ${ }^{[35]}$ 等，表明 $Y U C$ 基 因家族在陆生植物的进化上是保守的(表1).

$T A A 1$ 和 $Y U C$ 基因的共表达(co-expression)显著增 加拟南芥中IAA的水平和高生长素表型 ${ }^{[31]}$. TAA 和 $Y U C$ 基因家族的多重敲除突变体在不同的植物物种中表现 出IA A 水平的显著减少和严重的生长素缺陷表

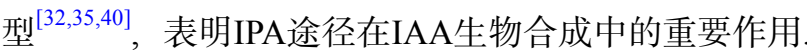
研究发现，L-犬尿氨酸(L-kynurenine)和L-氨基氧基苯 基丙酸(L-amino-oxyphenylpropionic acid，L-AOPP)是 TAA的抑制剂，yucasin是YUC的抑制剂 ${ }^{[50 \sim 52]}$. 应用L犬尿氨酸降低拟南芥中内源IAA的水平，引起类似于 wei8-1 和wei8 tar2缺失突变体的生长素缺陷表型 ${ }^{[50]}$. 用 L-AOPP处理的拟南芥幼苗也表现出IAA水平降低，以 及根伸长、根毛形成和根向地性缺陷 ${ }^{[52]}$. 在玉米胚芽 鞘中，yucasin显著减少IAA的生物合成和抑制向地性 反应 ${ }^{[51]}$. 这些基于化学生物学的研究表明, IPA途径是 植物中IAA生物合成的主要途径.

在拟南芥中, 吡哆醛磷酸依赖的氨基转移酶(pyridoxal phosphate-dependent aminotransferase)VAS1通过 转化IPA成为 Trp来调控IAA的生物合成 ${ }^{[53]}$. vas 1 敲除突 变体表现出IAA和与高生长素表型相联系的乙烯前体 1-氨基环丙烷-1-羧酸(1-aminocyclopropane-1-carboxy- late, ACC)的水平增加. VAS1可能利用乙烯前体甲硫氨 酸作为氨基供体、IPA作为氨基受体来产生 Trp和2-氧4-甲基硫代丁酸(2-oxo-4-methylthiobutyric acid). VAS1 的发现为IAA和乙烯生物合成的协同调控提供了新的 观点 ${ }^{[18]}$.

\subsubsection{IAOx途径合成IAA}

许多遗传和生化研究表明，IAOx途径在拟南芥 IAA生物合成中起辅助作用 ${ }^{[36,54]}$. 在IAOx途径的最初 步骤中, CYP79B2和CYP79B3催化Trp转化为IAOx(图 $1)^{[18]}$. 在拟南芥中, IAOx 是IAA和次生代谢物，包括芸 薹葡糖硫苷(glucobrassicin, GB)和植保素(camalexin)的 共同前体(图1) ${ }^{[18,36]}$. IAOx途径可能是芸菫科植物中的 一条物种专一的途径，因为 $C Y P 79 B$ 基因主要局限于该 科植物中 (表 1$)^{[18,36,55]}$. IG生物合成突变体surl(superroot 1)、sur2(superroot 2)/cyp83b1和ugt74b1表现出 $\mathrm{IAA}$ 和IAOx水平增加 ${ }^{[36,43]}$ 以及高生长素表型 ${ }^{[56]}$. 从 $\mathrm{IG}$ 到IAA的代谢通量增加，表明IAA和IG生物合成之间有 一种紧密的代谢联系. 在体外, CYP79B2和CYP79B3都 能催化Trp转化成为IAOx. 在拟南芥中, 这些Cyt P450 单加氧酶负责IAOx的产生, 因为在cyp79b2 cyp79b3双 敲除突变体中未检测到内源IAOx ${ }^{[36]}$. CYP79B2 的过表 达增加内源IAA水平，导致高生长素表型，例如延长的 下肧轴，这表明CYP79B2是催化IAOx途径中的限速步 骤 ${ }^{18]}$.

CYP79B2的启动子-GUS报告基因融合的分析表 明，该基因在幼根、子叶和维管组织中的表达相对较 高. 在正常生长条件下, cyp79b2 cyp79b3双突变体的表 型不明显，其幼苗比野生型植株稍小; 然而，在高温条 件下，cyp79b2 cyp79b3双突变体植株表现出比野生型 
植株更短的下胚轴和更小的子叶 ${ }^{[36]}$. 因此, IAOx途径 被认为在高温条件下起重要作用. 与该假设一致, 光敏 色素相互作用因子4(phytochrome-interacting factor 4, PIF4)在温度升高时活化CYP79B2、TAA1 和 YUC4基 因 ${ }^{[57]}$. 研究表明, 高温诱导microRNA和miR10515的表 达水平, 降低 $S U R l$ 的表达水平, 以及通过阻断 $\mathrm{IG}$ 的生 物合成来增加 IAA 的水平 ${ }^{[54]}$. 在较高的温度下, miR10515敲除突变体的低生长素表型变得更为严重, 表明IAOx途径与拟南芥的生长表型密切相关.

值得注意的是, 从IAOx到IAA的合成途径不清楚 (图1). IAM和吲哚-3-乙腈(indole-3-acetonitrile, IAN)被 认为是可能的前体, 因为这两种前体表现出类似于 IAOx的代谢谱 ${ }^{[36]}$. 例如在cyp79b2 cyp79b3双突变体中, IAM和IAN(除IAOx 外)的内源水平被显著降低. 此外, 当用 ${ }^{13} \mathrm{C}$ 标记的IAOx饲喂 $c y p 79 b 2$ cyp79b3 双突变体时, ${ }^{13} \mathrm{C}$ 被有效地掺人到IAM、IAN和IAA中。在拟南芥和 玉米中, 腈水解酶(nitrilase, NIT)家族能够转化IAN成 为 $\operatorname{IAA}(\text { 表 } 1)^{[18,58]}$. 然而, 在拟南芥中IAN和NIT可能在 IG代谢、植保素稳态(homeostasis)和氧化物解毒中而 不是在IAOx依赖的IAA生物合成中起主要作用 ${ }^{[34,59]}$.

此外, 研究表明, CYP79A2是一种拟南芥CYP79B2 和CYP79B3的同源物, 能够催化苯丙氨酸(phenylalanine)转化为苯基乙醛肪(phenyl acetaldoxime, PAOx), 但在体外具有较窄的底物特异性. 在拟南芥中, CYP79A2的过表达显著地增加苯基硫代葡萄糖苷(phenyl glucosinolate)的水平. 在cyp79b2 cyp79b3双突变体 中, 内源 $\mathrm{GB}$ 的水平表现出显著的降低 $(<0.01 \%)^{[60]}$. Irmisch等人 ${ }^{[61]}$ 发现, 玉米CYP79A61能够在异源系统中 产生PAOx 和IAOx, 以及促进生长素的形成和植物的防 御反应.

\subsection{3 其他的IAA生物合成途径}

Mano和Nemoto ${ }^{[37]}$ 提出, 植物也能从IAM途径产生 IAA(图1). 在玉米和水稻中已经检测到IAM, 但未检测 到IAOx(表1 $)^{[18,37,62]}$. iaaM(TRYPTOPHAN 2-MONOOX$Y G E N A S E)$ 基因的过表达增加IAA的水平，导致植物中 高生长素表型, 表明植物在体内能够转化IAM成为 IAA. 拟南芥酰胺酶1(Arabidopsis amidase 1, AtAMI1) 和烟草 (Nicotiana sp.)中的同源基因在体外能够转化 IAM成为 $I_{A A}{ }^{[37,63]}$. 然而, 在植物中还没有发现催化 IAM途径最初步骤的酶, 尽管生物信息学研究表明 $A M I 1$ 家族成员在高等植物中广泛分布 ${ }^{[37]}$, 但现有的证 据还不足以提出IAM途径是植物中IAA生物合成的主
要途径.

TAM和IAAld也被认为是植物中IAA的可能前体 (图1) ${ }^{[18,64]}$. 这些代谢物已经在许多植物物种中被检测 到 ${ }^{[62]}$. 此外, 当用氝标记的Trp处理时, 在踠豆 (Pisum sp.)根中观察到高水平的氞掺人到TAM和IAAld中, 表 明TAM和IAAld有助于豌豆根系从Trp生物合成IAA ${ }^{[65]}$. 色氨酸脱羧酶(Trp decarboxylase, TDC)家族能够转化 Trp成为TAM; 然而, TDC成员不可能促进IAA的生物 合成, 因为长春花(Catharanthus)TDC基因的过表达会 引起烟草中TAM水平的增加, 但不增加IAA水平 ${ }^{[18]}$. 乙 醛氧化酶(aldehyde oxidase, AAO)家族催化IAAld转化 成为IAA, 也被认为是IAA生物合成酶 (表 1$)^{[18]}$. 研究表 明, $\mathrm{AAO}$ 活性的丧失不引起拟南芥中生长素缺陷的表

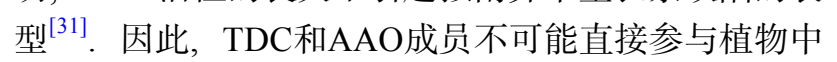
IAA的生物合成.

根据Trp生物合成突变体中代谢物的定量分析和 饲喂试验，Trp不依赖的途径被认为是玉米和拟南芥中 IAA生物合成的另一条途径 ${ }^{[18]}$. 当 ${ }^{15} \mathrm{~N}$ 标记的邻氨基苯 甲酸(anthranilate, ANT)饲喂给拟南芥Trp生物合成突 变体 $\operatorname{trp} 2-1$ 时, ${ }^{15} \mathrm{~N}$ 掺人到IAA中的水平比 $\operatorname{Tr} p$ 更高. 因 此, IAA被认为主要是由 Trp前体, 例如吲哚(indole, IND)和吲哚-3-甘油磷酸(indole-3-glycerol phosphate, IGP)产生的, 而不是来自 $\operatorname{Trp}(\text { 图1 })^{[18]}$. 由于反义 IGP合 酶(antisense IGP synthase, IGS)转基因株系中IAA水平 被显著降低, IGP被认为是拟南芥 Trp不依赖途径中的 一个分支点中间物; 然而, 当利用基于碱性水解定量法 测定时, Trp生物合成突变体 trp 3-1 和 trp 2-1 中的IAA水 平显著增加. 由于trp3-1突变体中IGP和GB的水平显著 增加, 以及IAA水平的明显增加是由碱性水解过程中 IGP和GB降解形成的, 因此, Trp不依赖途径被认为是 一种人工产物 ${ }^{[18]}$. $\mathrm{Yu}$ 等人 ${ }^{[66]}$ 报道, 碱处理后产生的大 部分IAA可能归因于化学转化而不是IAA结合物的水 解. 特别是 $\mathrm{GB}$ 的转化曾经被认为以很低的水平发生, 但实际上可能占释放IAA的大部分. 另外, 高水平的 IAA也可能来源于蛋白的Trp降解, 这些结果进一步证 明 Trp不依赖途径中的IAA及其代谢物水平的增加很可 能是来自 $\mathrm{GB}$ 和蛋白 $\operatorname{Trp}$ 的化学转化所产生的 $\mathrm{IAA}^{[66]}$, 弱 化了 Trp不依赖途径的生化证据, 表明在植物中IAA主 要从 $\operatorname{Trp}$ 产生.

Wang等人 ${ }^{[67]}$ 报道，细胞质定位的吲哚合酶(indole synthase, INS)是一种质体定位的 Trp合酶 $\alpha$ 亚基结构域 (Trp synthase $\alpha$-subunit domain, TSA)/TRP3的旁系同 
源物, 在拟南芥 Trp不依赖的途径中起作用. INS产生的 IND作为细胞质中IAA的一种初始前体, 从IND到IAA 的合成途径还不清楚. 在ins 突变体的幼苗中内源IAA 的水平轻微下降, 然而, 在 $t r p 3-1$ 和 $t r p 2-1$ 突变体的幼苗 中IAA的水平增加. 在早期胚胎发生过程中, INS在顶基轴向模式(apical-basal pattern)的建立中起重要作用, 表明 Trp依赖的和 Trp不依赖的IAA生物合成途径协同 调控高等植物的胚胎发生. Trp不依赖途径的遗传和生 化研究将有助于进一步理解该途径在IAA生物合成中 的作用.

\subsection{IAA分解代谢与失活}

植物细胞中生物活性IAA的水平是由合成、运 输、储存和失活之间的平衡决定的. 生长素信号在局 部积累后的失活以及生长素最适值的调节对于植物生 长发育是非常重要的 ${ }^{[17]}$. 实际上, 植物细胞中只有 $25 \%$ 的IAA以游离的形式存在 ${ }^{[68]}$, 大部分IAA通过形成暂时 的储存形式或者通过不可逆的代谢降解而失活. 在不 同的植物物种中已经发现了几种IAA的失活形式 ${ }^{[62]}$, 其中一些形式可以转化回到游离的IAA, 从而精确地调 控IAA的浓度.

\subsubsection{IAA的结合、储存与释放}

氨基酸、肽和蛋白能够通过酰胺键与IAA结合 ${ }^{[62]}$. 虽然IAA-肽和IAA-蛋白的功能还不清楚，但IAA-氨基 酸结合物的特性已经被广泛研究. 酰基酸酰胺合成酶 (acyl acid-amido synthetase)的GH3(GRETCHEN HAGEN 3)家族成员最初在大豆(Glycine max)中被鉴定为 早期生长素反应基因 ${ }^{[17]}$. 在拟南芥中, GH3组 II 家族 (GH3 group II family)的8个成员将IAA与不同的氨基 酸结合 ${ }^{[69]}$. 拟南芥单个 $g h 3$ 突变体对IAA的敏感性较低, 但在无激素的培养基上生长时类似于野生型植株 ${ }^{[69]}$. 只有高阶(high-order)gh3突变体表现出IAA含量增加和 生长素过量表型, 包括增加根分支和伸长叶柄 ${ }^{[70]}$. 尽管 GH3 存在普遍的圥余, 但仍有一定程度的专一性. 例如, 在对遮阴和高温的反应中 GH3 3 .17调节拟南芥下胚轴中 活性IAA的水平 ${ }^{[71]}$. 一些 $\mathrm{GH} 3$ 被认为是具有多功能的 酶, 能将氨基酸与不同的植物激素结合 ${ }^{[69]}$. 例如, IAA 酰胺合成酶GH3.3、GH3.5 和GH3.6能将Asp、Met和 $\operatorname{Trp}$ 与茉莉酸(jasmonic acid)结合, 从而正调控不定根的 发育 ${ }^{[72]}, \mathrm{GH} 3.5$ 将水杨酸(salicylic acid, SA)或者苯甲酸 (benzoic acid)与生长素PAA结合 ${ }^{[73]}$.

IAA酰胺水解酶(IAA amidohydrolases)将一些
IAA-氨基酸结合物转化成为游离的IAA，有助于调控 IAA的水平. 在拟南芥中, 这些酰胺水解酶包括ILR1 (IAA-leucine resistant1)、IAR3(IAA-alanine resistant3) 和5 个ILL(ILR1-like), 它们对IAA-氨基酸底物具有广泛 的体外活性，例如IAA-Leu、IAA-Ala、IAA-Phe和 IAA-Gly 等 ${ }^{[17]}$. 与外源IAA所引起的表型比较, 用这些 结合物处理的植物表现出根系生长抑制, 表明这些结 合物是调控植物中生长素代谢的IAA储存形式 ${ }^{[17,74]}$. 拟 南芥ilr1 iar3ill2突变体植株具有较低的IAA水平, 积累 IAA-Ala和IAA-Leu, 表现出生长缺陷, 例如缩短的下肧 轴和减少的根分枝 ${ }^{[74]}$. 最丰富的IAA-氨基酸结合物 IAA-Asp和IAA-Glu不是可逆的IAA储存形式，但是分 解的代谢产物; 用标记的IAA-Asp和IAA-Glu饲喂拟南 芥植株后, 没有检测到标记的IAA, 而且ilr1 iar3 ill2酰 胺水解酶突变体中的IAA-Asp和IAA-Glu水平与野生 型类似 ${ }^{[17]}$.

研究发现, 酯连接的IAA-糖(IAA-sugar)共轭物存 在于许多植物物种中，包括拟南芥、大豆、玉米和水 稻, 这些IAA结合物在几种谷类和豆科植物的种子中 是非常丰富的 ${ }^{[17]}$. IAA-糖是欧洲赤松(Pinus sylvestris) 种子中的主要IAA形式，在种子萌发后 $4 \mathrm{~d}$ 开始从头合 成IAA，表明IAA-糖是一些物种在幼苗早期形成过程 中IAA的主要来源 ${ }^{[75]}$. 已经在玉 ${ }^{\left[{ }^{[76]}\right.}$ 和水稻 $^{[77]}$ 种子中 鉴定了IAA-葡糖水解酶(IAA-glc hydrolase), 并确定水 稻IAA-glc水解酶TGW6 与粒重有关 ${ }^{[77]}$. 在拟南芥中, IAA-glc是最普遍的IAA酯结合物, 也是幼苗组织中最 丰富的IAA代谢物, 在根中的含量特别高 ${ }^{[70]}$. 专一的尿 苷二磷酸糖基转移酶(uridine-diphosphate (UDP) glycosyltransferases, UGT)催化UDP-glc与IAA的结合, 已经 在玉米(IAGLU)和拟南芥(UGT84B1)中被鉴定. 拟南芥 中 $A t U G T 84 B 1$ 和ZmIAGLU的过表达引起IAA-glc的积 累, 降低对外源IAA的敏感性 ${ }^{[17]}$. 不同植物的IAA-糖基 转移酶(IAA glycosyltransferase)和IAA-glc水解酶功能 缺失突变体的分离和鉴定将有助于揭示IAA酯结合物 对IAA代谢和植物发育的作用.

IAA甲酯(methyl ester of IAA, MeIAA)也被认为是 一种与IAA代谢有关的储存形式. 拟南芥IAA羧基甲基 转移酶(IAA carboxyl methyltransferase, IAMT)在体外 能使IAA的羧基甲基化. IAMTI在拟南芥幼苗中普遍表 达，其RNAi敲除导致发育缺陷，包括矮化和育性降 低 ${ }^{[78]}$. IAMT1 T-DNA插人突变体的研究表明, 在拟南芥 下胚轴的重力感受过程中MeIAA在生长素梯度形成中 
具有特异性作用 ${ }^{[79]}$. 外源MeIAA抑制暗生长幼苗的根 生长和下胚轴伸长, 其抑制作用与IAA的作用相似, 表 明MeIAA调控内源IAA水平 ${ }^{[78]}$. 事实上, 拟南芥IAA甲 基酯酶17(IAA methylesterase 17, AtMES17)水解MeIAA 结合物成为游离 $\mathrm{IAA}^{[80]}$. mes 17 植株的根生长对 MeIAA 的敏感性较低, 饲喂试验表明mes 17 植株仅仅能水解 $40 \%$ 的 ${ }^{14} \mathrm{C}$-MeIAA, 这说明其他的MES攵余地促进 MeIAA的水解 ${ }^{[80]}$. MeIAA本身不能被生长素-共受体复 合物识别, 不干扰IAA的作用 ${ }^{[79]}$, 这进一步支持MeIAA 对植物发育的影响归因于水解产生的IAA的假设.

吲噪-3-丁酸(indole-3-butyric acid, IBA)能够被过 氧化物酶体(peroxisome)中的酶以类似于脂肪酸 $\beta$-氧化 的过程转化为 $\mathrm{IAA}^{[81]}$. IBA $\beta$-氧化途径的突变体对IBA 不敏感, 但对IAA敏感, 这表明IBA本身是没有活性的, 任何生长素反应完全归因于其转化生成的 $\mathrm{IAA}^{[81]}$. 研 究表明, 从IBA衍生的IAA在根和茎发育的许多不同方 面起专一的作用, 例如, 侧根的启动似乎高度依赖于侧 根帽中的IBA转化成为 $\mathrm{IAA}^{[82]}$.

\subsubsection{IAA的氧化}

通过形成2-氧吲哚-3-乙酸(2-oxindole-3-acetic acid, oxIAA)以及随后与葡萄糖结合 (oxIAA-glc)的IAA氧化 衰减(oxidative attenuation)被认为是IAA失活的主要途 径, 因为这些氧化代谢物的水平比其他IAA分解代谢 物高100倍 ${ }^{[83]}$, IAA处理迅速增加oxIAA和oxIAA-glc的 水平 ${ }^{[84]}$. 一个生殖发育受损的水稻突变体缺乏生长素 氧化的二加氧酶(dioxygenase for auxin oxidation, OsDAO)活性, OsDAO是一种2-氧戊二酸依赖的 Fe (II)二 加氧酶(2-oxoglutarate-dependent $\mathrm{Fe}$ (II) dioxygenase), 在体外能将IAA转化成为oxIAA ${ }^{[85]}$. 研究表明, 在 $d a o$ 的 花药和子房中IAA的水平增加, oxIAA的产生下降 ${ }^{[85]}$. 此外, oxIAA葡糖基化成为 $\mathrm{oxIAA}-\mathrm{glc}$ 至少部分被 UGT74D1酶催化 ${ }^{[86]}$. 已经在拟南芥中鉴定了 2 个 $D A O$ 同源基因 $A t D A O 1$ 和 $A t D A O 2$, 但oxIAA的产生似乎主要 依赖于AtDAO1的活性 ${ }^{[70]}$. 拟南芥根系中oxIAA水平的 细胞类型特异性定量表明, oxIAA的分布与根组织中 IAA的分布相一致 ${ }^{[83]}$, 表明IAA的氧化参与生长素梯度 的形成. 这一结果被dao1-1突变体根系中IAA分布的数 学模拟所支持 ${ }^{[70,87]}$.

\section{IAA信号转导}

IAA信号转导途径包括典型和非典型生长素信号 转导途径 ${ }^{[19,20,26,27]}$. 在典型的生长素信号转导途径(ca- nonical auxin signaling pathway)中, 生长素与TIR1/ AFB(transport inhibition resistant1/auxin signaling Fbox)家族的F-box蛋白和Aux/IAA(auxin/indole-3-acetic acid)转录抑制因子结合, $\mathrm{SCF}^{\mathrm{TIR} 1 / \mathrm{AFB}} \mathrm{E} 3$ 泛素连接酶复 合物将活化的泛素(ubiquitin)转移到Aux/IAA上, Aux/ IAA的多泛素化导致其通过 $26 \mathrm{~S}$ 蛋白酶体降解并解除 对ARF的抑制, 活化生长素诱导基因的转录(图2 ${ }^{[19,20]}$. 非典型生长素信号转导途径(non-canonical auxin signaling pathway)主要包括TIR1、ETTIN和类受体激酶 介导的途径, 但生长素结合的下游事件仍然不清楚 ${ }^{[26]}$.

\section{1 典型的生长素信号转导}

典型的生长素信号转导途径的核心组分包括 TIR1/AFB、Aux/IAA和ARF，它们相互作用完成生长 素控制的基因转录. 在拟南芥中含有 6 个 TIR $1 / A F B$ 同 源成员, 29 个Aux/IAA同源成员以及 3 种类型的 $\mathrm{ARF}^{[20]}$.

\subsubsection{TIR1/AFB}

TIR 1/AFB蛋白被整合到一个含有 4 个亚基的 $\mathrm{SCF}^{\mathrm{TIR} 1 / \mathrm{AFB}}$ 复合物中, 这个复合物和小分子Aux/IAA蛋 白都定位于细胞核中, 所有的TIR1/AFB蛋白都能与生 长素结合 ${ }^{[88,89]}$. 研究表明, 4个TIR1/AFB家族成员促进 生长素反应; 这些成员的单突变体(tirl、afb2和 $a f b 3)$ 具 有弱的生长素抗性, 其高阶突变体(higher-order mutant) $a f b 1$ 具有强的生长素抗性 ${ }^{[88,89]}$. tir $1 / a f b$ 突变体也表现出 与生长素感受一致的形态缺陷. $\mathrm{SCF}^{\mathrm{TIR} 1 / \mathrm{AFB}}$ 泛素连接酶 复合物的其他组分, 如ASK1(Arabidopsis SKP1 homologue)、CUL1(Cullin 1)或者RBX1(ring-box 1)的突变 体也引起生长素抗性 ${ }^{[90]}$.

TIR 1/AFB家族成员具有一个 $N$-端富含亮氨酸重 复的区域和一个C-端F-box结构域(图2(a)) ${ }^{[20]}$. 与 TIR1 和AFB1 3不同, AFB4和AFB5 具有额外的蛋白结构域, 并与生长素类似物结合 ${ }^{[11]}$. 包含生长素和小分子 $\mathrm{Aux} /$ IAA蛋白复合物 TIR 1-ASK 1 的晶体结构解析表明, TIR1/AFB中富含亮氨酸重复的结构域含有生长素结 合口袋，而F-box结构域与ASK1接触; Aux/IAA蛋白也 在生长素结合位点与富含亮氨酸重复的结构域接 触 ${ }^{[92]}$. 这些结果表明, 生长素能够稳定TIR1/ASK和 Aux/IAA蛋白之间的相互作用 ${ }^{[93]}$. TIR1/AFB蛋白也通 过F-box结构域与 $\mathrm{SCF}^{\mathrm{TIR} 1 / \mathrm{AFB}}$ 复合物的CUL1亚基接触, 这与自动催化的降解相联系 ${ }^{[94]}$.

\subsubsection{Aux/IAA}

Aux/IAA蛋白不含DNA结合基序, 而是由ARF蛋白 
(a) TIR1/AFB

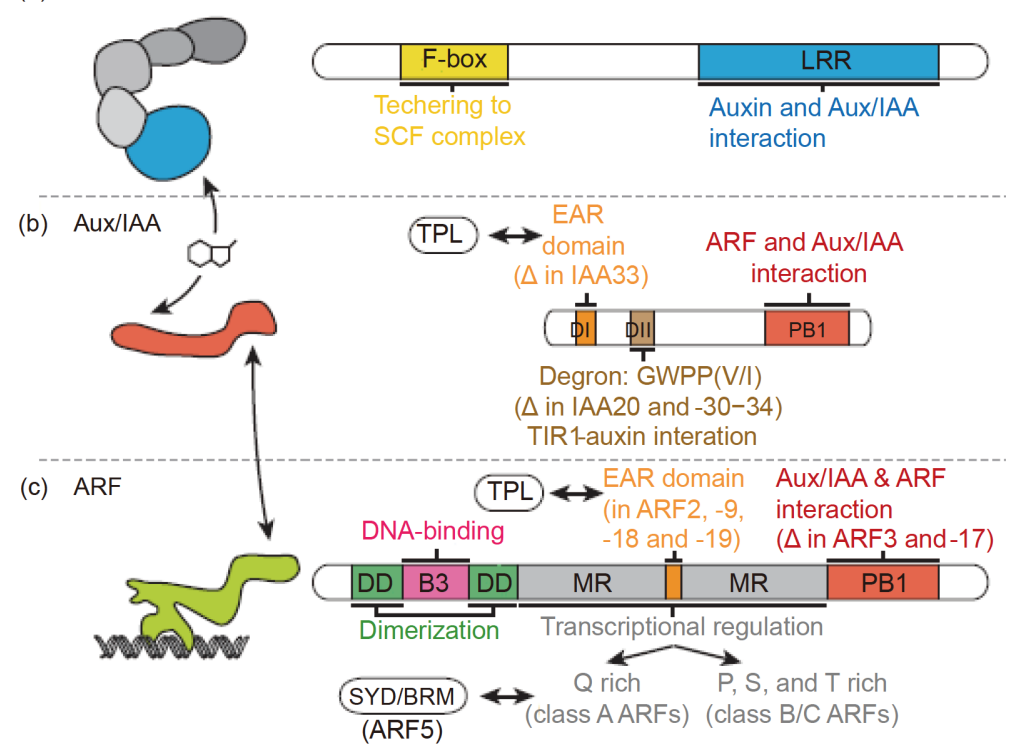

图 2 生长素依赖的基因调控的核心组分的域结构 ${ }^{[20]}$. 生长素反应由 3 个核心组分之间的相互作用(箭头)介导: (a) TIR1/AFB生长素受体, (b) Aux/IAA转录抑制因子和(c) ARF转录因子. TIR1/AFB蛋白含有一个F-box结构域和一个富含亮氨酸重复(LRR)的结构域. F-box结构域与SCF E3 泛素连接酶复合物中的其他亚基结合, LRR结构域携带生长素结合口袋和Aux/IAA接触位点. Aux/IAA蛋白由结构域1(D I )、结构域2(D II)和 PB1结构域组成. 结构域1(IAA33缺失)含有一个介导与TPL相互作用的EAR基序; 结构域2(IAA20和-30-34缺失)携带降解决定子(保守的氨基酸 序列为GWPP(V/I), 作为与TIR1/AFB和生长素的接触位点起作用); PB1结构域介导寡聚化和Aux/IAA-ARF异源二聚化. ARF含有一个 $\mathrm{N}-$ 端B3 DNA结合结构域, B3结构域的两侧各有一个二聚结构域(DD), 随后是介导转录调控的中间区域(MR). 在ARF2、-9、-18和-19中, MR中间区域 可能包含一个与TPL相互作用的EAR基序; 在类型 $A$ ARF中富含谷氨酰胺 $(\mathrm{Q})$, 但在类型B和C ARF中富含脯氨酸 $(\mathrm{P}) 、$ 丝氨酸 $(\mathrm{S})$ 和苏氨酸 $(\mathrm{T})$. 在 ARF5中, 这个结构域介导与SYD和BRM的相互作用. 在其C-端, ARF(除ARF3和-17外)都含有一个塞聚化和Aux/IAA-ARF异源二聚化的PB1结 构域. ARF, 生长素反应因子; Aux/IAA, 生长素/吲哚-3-乙酸蛋白; BRM, BRAHMA; EAR, 乙烯反应元件结合因子相关的抑制因子; PB1, Phox and Bem 1; SYD, SPLAYED; TIR1/AFB, 运输抑制因子抗性1/生长素信号转导F-BOX; TPL, TOPLESS

Figure 2 Domain architecture of central components of auxin-dependent gene regulation ${ }^{[20]}$. Auxin responses are mediated by interactions (arrows) between three core components: (a) TIR1/AFB auxin receptors, (b) Aux/IAA transcriptional repressors, and (c) ARF transcription factors. TIR1/AFB proteins contain an F-box domain for tethering to the other subunits in the SCF E3 ubiquitin ligase complex and a leucine-rich-repeat (LRR) domain that carries the auxin-binding pocket and Aux/IAA contact site. Aux/IAA proteins consist of domain 1 (DI, missing in IAA33), which harbors an EAR motif that mediates interaction with TPL; domain 2 (DII, missing in IAA20 and -30-34), which carries the degron (the conserved amino acid sequence GWPP (V/I), which acts as the contact site with TIR1/AFB and auxin); and a PB1 domain, which mediates oligomerization and Aux/IAA-ARF heterodimerization. ARFs have an N-terminal B3 DNA-binding domain flanked on either side by a dimerization domain (DD), followed by a middle region (MR) that mediates transcriptional regulation. This domain can contain an EAR motif (in ARF2, -9, -18, and -19) for interaction with TPL; it is glutamine $(\mathrm{Q})$ rich in class A ARFs but proline $(\mathrm{P})$, serine $(\mathrm{S})$, and threonine $(\mathrm{T})$ rich in class B and C ARFs. In ARF5, this domain mediates the interaction with SYD and BRM. At their C termini, ARFs (with the exception of ARF3 and -17) have a PB1 domain for oligomerization and Aux/IAAARF heterodimerization. ARF, auxin response factor; Aux/IAA, auxin/indole-3-acetic acid protein; BRM, BRAHMA; EAR, ethylene-responsive element binding factor-associated repressor; PB1, Phox and Bem 1; SYD, SPLAYED; TIR1/AFB, transport inhibitor resistant 1/auxin signaling F-box; TPL, TOPLESS

招募到基因组区域, 它们与ARF蛋白一起通过共享的C端结构域进行物理相互作用(图2(b) $)^{[20,95]}$. Aux/IAA蛋 白通常含有一个或者两个 $\mathrm{N}$-端乙烯反应元件结合因子 相关的抑制因子(ethylene-responsive element binding factor-associated repressor, EAR)或者类EAR(EAR-like) 抑制因子基序(结构域1(domain1, D I ))、一个TIR1/ AFB相互作用和降解必需的中心区域(降解决定子(degron), 或者结构域2(domain2, D II )) 以及一个介导同源 和异源二聚作用的C-端PB1(Phox and Bem 1)蛋白-蛋白 相互作用的结构域(图2(b)) ${ }^{[20,96]}$. 研究表明, Aux/IAA蛋 白以头-尾排列(head-tail configuration)的多聚化是由 PB1结构域介导的 ${ }^{[97]}$; 不同的Aux/IAA蛋白对生长素具 有明显不同的敏感性, 半衰期从几分钟到几小时 ${ }^{[98]}$.

单个Aux/IAA蛋白在结构域的存在和保守性方面 显著不同, 这些差异对于生长素的敏感性/蛋白稳定性 以及与TIR1的联系是重要的 ${ }^{[98]}$, 其中最重要的是降解 决定子(结构域2)以及结构域1和结构域2之间的一对保 守的氨基酸, 即赖氨酸和精氨酸(lysine and arginine, $\mathrm{KR}$ )(图2(b)). 典型的降解决定子和KR基序的存在增加 了共受体(TIR1/AFB-Aux/IAA)对生长素的亲和力, 导 
致Aux/IAA蛋白的稳定性下降(在较低的生长素浓度下

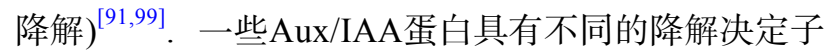
或者完全缺乏该结构域, 这将分别引起对生长素的敏 感性降低或者不敏感 ${ }^{[91,98,99]}$. 降解决定子的突变使得 Aux/IAA蛋白对生长素不敏感, 可能是因为降解决定 子中的核心残基直接与 TIR 1 -生长素复合物相互作 用 ${ }^{[92]}$. 携带一个赖氨酸-谷氨酰胺(lysine-glutamine, KQ) 基序或者没有 KR基序的Aux/IAA也表现出对生长素的 敏感性降低 ${ }^{[91,98,99]}$. 降解决定子下游极性氨基酸的存在 增加与TIR1/AFB的相互作用, 极性氨基酸的突变导致 Aux/IAA蛋白的功能获得表型，这种表型类似于降解 决定子基序的突变, 但比后者的表型更弱 ${ }^{[99]}$.

Aux/IAA蛋白通过共抑制因子复合物(corepressor complex)的招募抑制在其靶点结合的活化ARF. Aux/ IAA蛋白结构域 1 中的EAR抑制因子基序与称为 TPL (topless)或者TPR(topless related)的Tup1/Groucho/TLE 家族蛋白物理相互作用并招募它们 ${ }^{[100,101]}$. TPL和Aux/ IAA EAR结构域之间的共晶体解析表明, 这种相互作 用需要TPL N-端的CTLH区域 ${ }^{[101]}$. EAR基序与TPL的 相互作用区域形成一个四聚体，该四聚体与寡聚的含 有EAR结构域的伴侣的相互作用更强 ${ }^{[97]}$.

一旦生长素与TIR1/AFB蛋白中的结合口袋结合, 将对Aux/IAA蛋白的亲和性增加 ${ }^{[92]}$. Aux/IAA蛋白随后 被泛素化并在26S蛋白酶体中降解 ${ }^{[102]}$. 虽然泛素化已经 在原生质体分析中被证明 ${ }^{[102]}$ ，但在体内泛素化的位置 和程度还不够清楚. Gilkerson等人 ${ }^{[103]}$ 提出, 泛素化可能 比最初的假设更为复杂. 研究表明, 即使拟南芥IAA1中 所有 16 个赖氨酸被突变, 消除所有可能的典型的泛素受 体位点, 但IAA1蛋白仍然是不稳定的且被泛素化. 药物 处理表明, 生长素依赖的IAA1泛素化可能包括与丝氨 酸、苏氨酸或者半胱氨酸中非典型的氧酯键(oxyester). 由于这些残基都能被翻译后修饰, 如磷酸化(phosphorylation)或者形成二硫键(disulfide bridge), 表明Aux/IAA 蛋白的修饰能够影响生长素依赖的降解能力.

\subsubsection{ARF}

生长素转录反应的关键是 $\mathrm{ARF}$ 家族的序列专一性 转录调控因子. ARF蛋白与称为生长素反应元件(auxin response element, AuxRE)的顺式调控序列(cis-regulatory sequence)结合, 顺式调控序列的核心含有一个足 以招募ARF蛋白的 TGTC基序 ${ }^{[20]}$. 结构分析和蛋白芯片 数据表明, 不同的拟南芥ARF(ARF1、-3和-5)优先与较 大的TGTCGG基序结合 ${ }^{[104]}$. 从早期陆生植物开始,
ARF蛋白分为 3 种类型(图2(c) $)^{[20,105,106]}$. 类型A由具有 一个富含谷氨酰胺(glutamine, Q)中间区域的ARF组成, 根据在原生质体中的瞬时基因表达分析，这些ARF被 分类为转录活化因子. 富含 $\mathrm{Q}$ 的结构域存在于所有类型 $\mathrm{A}$ 的ARF中 ${ }^{[105,106]}$. 根据相同的原生质体分析或者序列 同源性，剩余的 $\mathrm{ARF}$ 被分类为抑制因子、能够再分为 microRNA 160 (miR160) 靶定的 $\mathrm{ARF}$ (类型 $\mathrm{C}$ )和其他的 $\mathrm{ARF}($ 类型B $)(\text { 图2(c) })^{[20]}$. ARF DNA结合区域的结构分 析表明, B3 DNA结合结构域被嵌人在 $A R F$ 二聚结构域 中, $\mathrm{ARF}$ 蛋白优先与反向的AuxRE重复结合 ${ }^{[104]}$. 大多数 但不是所有的ARF都含有一个C-端PB1结构域(图2(c)), 这对于ARF和Aux/IAA蛋白之间的物理相互作用是重 要的 ${ }^{[97,107]}$. 在低生长素条件下, Aux/IAA蛋白专一地抑 制ARF的转录活性. PB 1 结构域也可能有助于ARFARF的二聚作用 ${ }^{[96,97,107]}$.

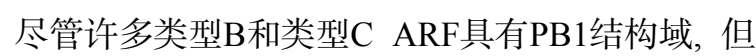
大多数似乎不与 Aux/IAA蛋白强烈地相互作用 ${ }^{[108]}$. Richter等人 ${ }^{[109]}$ 提出，类型 $\mathrm{B}$ 和类型 $\mathrm{C} A \mathrm{ARF}$ 可能以生长 素不依赖的方式干扰类型A ARF的活性，例如通过竞 争DNA结合位点或者通过异源二聚作用阻断活化的 ARF活性. 一些类型B(抑制的)ARF(ARF2、-9和-18)和 一个单一的类型A ARF(ARF19)都含有一个EAR结构 域，这个结构域与共抑制因子复合物的招募有关 ${ }^{[100]}$ 研究已经发现, 类型A ARF抑制某些靶基因 ${ }^{[110]}$, 对于 生长素依赖的基因抑制目前还没有满意的模型.

在低生长素条件下，抑制生长素反应基因的表达 还需要组蛋白去乙酰化酶(histone deacetylase, HDAC), 如HDA19.HDA19活性的圭失能部分恢复与Aux/IAA 编码基因中功能获得突变相关的表型，以及 TPL和 HDA19被招募到活化的ARF结合位点, 特别是在低生 长素条件下 ${ }^{[111]}$. 在植物中TPL招募HDAC复合物 ${ }^{[112]}$, $\mathrm{HDAC}$ 从组蛋白(主要是组蛋白H3和H4)的赖氨酸残基 上去除乙酰基，导致染色质状态更加致密并降低基因 组DNA对转录因子或者转录复合体的可及性(accessibility). 当Aux/IAA水平增加、生长素水平降低时, 致密 的染色质阻止生长素反应基因的表达. 生长素水平的 增加引起Aux/IAA蛋白降解以及TPL和HDAC从活化 的 $\mathrm{ARF}$ 靶点逐出, 但留下致密的染色质 ${ }^{[111]}$. 当生长素被 感受时, 另一类染色质调控蛋白SWI/SNF(switch/sucrose nonfermenting), 如染色质重塑ATP酶有助于克服 这种被抑制的染色质状态. SWI/SNF染色质重塑复合 物利用ATP水解的能量来改变核小体(nucleosome)在 
DNA上的占有或者定位，从而改变基因组DNA在染色 质中的可及性 ${ }^{[113]}$. 类型A ARF5/MP(monopteros)中富 含 $\mathrm{Q}$ 的中间区域与在 BRM(BRAHMA) 或者 SYD (SPLAYED)周围形成的植物SWI/SNF染色质重塑复合 物相互作用, 并招募这一复合物到MP靶点 ${ }^{[111]}$. BRM和 SYD是生长素反应基因表达所必需的，通过在MP靶点 解锁被抑制的染色质状态来完成这种作用，从而为其 他转录因子开放结合位点. 在低生长素条件下, SWI/ SNF重塑因子的招募被与MP结合的Aux/IAA蛋白所阻 断. SWI/SNF复合物与 MP靶点的结合能够恢复 $m p$ 突变 体的形态缺陷，表明SWI/SNF复合物的招募可能是MP 的一种主要功能.

\section{2 非典型的生长素信号转导}

生长素结合蛋白1(auxin binding protein 1, ABP1) 是一种对生长素具有高亲和力的结合蛋白，长期以来 被认为是细胞外生长素的受体，尤其是在快速的非转 录生长素反应中起重要作用 ${ }^{[114,115]}$. 然而, 随后的研究 发现, abp1突变体植株不表现出任何明显的发育缺陷, 在野生型和 $a b p 1$ 植株中已知的生长素调控基因对生长 素处理的反应也是相似的; 生长素信号转导以及在正 常生长条件下植物的发育都不需要 $\mathrm{ABP} 1^{[116]}$. 因此, $\mathrm{ABP} 1$ 被认为不是生长素信号转导或者拟南芥发育的 关键组分. 经典的生长素反应包括生长素被添加到原 生质体后质膜的迅速超极化(hyperpolarization)以及根 系对生长素的快速反应, 由于这些反应发生太快, 不能 用典型的生长素信号转导途径来解释 ${ }^{[117]}$. 根据拟南芥 根系对生长素添加和去除的快速反应, Fendrych等 人 $^{[118]}$ 提出, 这种快速反应需要细胞内生长素的感受, 而不需要转录重编程. 现有的证据表明, 非典型的生长 素信号转导途径也在植物的生长和发育中起作用，主 要包括TIR1、ETTIN和类受体激酶(receptor-like kinase, RLK)介导的途径 ${ }^{[26]}$.

\subsubsection{TIR1介导的途径}

利用生长素感受载体AUX1的敲除株系, 发现根伸 长生长的快速变化依赖于AUX1, 表明生长素信号感受 的部位在细胞内. 将微电极插人根毛细胞, 发现在对生 长素刺激的反应中质膜电位(plasma membrane potential)产生快速且AUX1依赖的变化 ${ }^{[119]}$. 单个或多个TIRI 和 $A F B$ 突变株系的研究表明, 这些反应也依赖于TIR1/ $\mathrm{AFB}^{[26,120]}$. 此外，通过一种凹凸(bump-and-hole)策略研 发了一种正交的生长素-TIR1受体对，它能触发生长素
信号转导, 但不干扰内源生长素或者TIR1/AFB. 在互补 的凹型TIR1(ccvTIR1)受体存在下，一种合成的凸型 IAA(cvxIAA) 在转录水平和特定的发育环境中在体内 劫持下游生长素信号. 利用cvxIAA-ccvTIR1系统, 证实 了幼苗中TIR1介导的途径在生长素诱导的酸生长 (acid growth)中起作用 ${ }^{[121]}$.

在对IAA的反应中，质膜去极化以一种IAA浓度和 $\mathrm{pH}$ 依赖的方式发生. 在aux 1 突变体中这种去极化被严 重地破坏, 表明AUX1是根毛中生长素吸收的主要转运 体. AUX1介导的IAA转运和IAA触发的钙信号被 $\mathrm{SCF}^{\mathrm{TIR} 1 / \mathrm{AFB}}$ 抑制剂auxinole阻断, 以及在 $t i r 1 a f b 2 a f b 3$ 和 cngcl 1突变体中被强烈地减少. 研究表明, AUX1转运 体、 $\mathrm{SCF}^{\mathrm{TIR} 1 / \mathrm{AFB}}$ 受体和CNGC 14(cyclic nucleotide-gate channel 14) $\mathrm{Ca}^{2+}$ 通道介导了根系中生长素信号的快速 转导 ${ }^{[119]}$.

\subsubsection{ETTIN介导的途径}

$\mathrm{ARF}$ 是一个转录因子家族，通过一个保守的 $\mathrm{N}$-端 DNA结合结构域与AuxRE结合 ${ }^{[19,20,122]}$. 大多数ARF也 包含一个保守的C-端PB1结构域, 该结构域在典型的生 长素信号转导途径中负责与Aux/IAA蛋白结合 ${ }^{[20]}$. 一 个称为ETTIN(ETT)的变体ARF3 具有一个长的和本质 上无序的C-末端结构域(ES结构域); 因为它不与 Aux/ IAA抑制因子相互作用，被认为是一种非典型的生长 素感受器, 调控发育必需的多种功能. ETT以IAA依赖 的方式控制生长，但这种作用不需要泛素化和 $\mathrm{TIR} 1^{[123,124]}$. ETT对生长素的感受能力依赖于其C-端的 ES结构域, 这个结构域能与一组可变转录调控因子(alternative transcriptional regulator)包括INDE(INDEHISCENT)、RPL(REPLUMLESS)和BP(BREVIPEDICELLUS)相互作用 ${ }^{[123,124]}$. 利用信息学、突变、酵母双杂和 表达技术, 发现ES结构域具有一个长片段, 这个长片段 具有很低的序列保守性但其中有一系列短的保守基

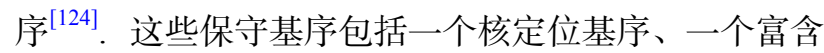
丝氨酸的激酶位点和另外三个尚未确定功能的位点. 大多数ES结构域似乎是相互作用所必需的，但当激酶 基序中任何丝氨酸残基被突变时，对IAA的敏感性丧 失 ${ }^{[125]}$. 值得注意的是, ETT对生长素的敏感性较低(通 常在50 100 $\mu \mathrm{mol} / \mathrm{L}$ IAA之间), 不被人工合成的生长素 $\alpha$-菜乙酸 $(\alpha$-naphthylacetic acid, NAA)或者 2,4 -二氯苯 氧乙酸(2,4-dichlorophenoxyacetic acid, 2,4-D)触发. 研 究还发现, ARF3的进化比典型的生长素信号途径出现 得更晚, 因此ETT是一个特殊的非典型途径 ${ }^{[26]}$. 


\subsection{3 类受体激酶介导的途径}

非典型生长素信号转导也被认为与不同的类受体 激酶有关, 包括D6蛋白激酶、PINOID蛋白激酶、有丝 分裂原活化的蛋白激酶(mitogen-activated protein kinases, MAPK)和质膜相关的激酶 ${ }^{[127]}$, 这些激酶通过调 节称为PIN的生长素输出蛋白的定位和活性来促进生 长素的作用; 激酶级联(kinase cascade)反应是迅速的以 及可能参与迅速的非典型的生长素信号转导. 研究表 明, MAPK级联参与了许多生长素调控的反应系统 ${ }^{[128]}$, 其作用包括RBK1(ROP binding protein kinase 1)的磷酸 化, 导致ROP(Rho-like GTPases from plant)成员的活化; ROP是小分子GTPase, 通常与细胞骨架和生长素运输 的调控有关 ${ }^{[128]}$.

跨膜激酶(transmembrane kinases, TMK)也与生长 素信号转导有关 ${ }^{[129]}$. TMK形成一个亚家族的植物RLK, 它们是一个大的和多样化的家族，其结构特征包括一 个作为活性结构域起作用的胞外结构域、一个跨膜结 构域和一个胞内激酶结构域，有时还具有一个磷酸传 递受体结构域(phosphorelay receiver domain) ${ }^{[26]}$. 最近, $\mathrm{Li}$ 等人 ${ }^{[130]}$ 发现了一种新的生长素信号转导机制, 它与 基于TIR1/AFB受体的典型生长素途径平行地起作用, 在拟南芥顶钩(apical-hook)发育过程中改变细胞生长素 水平以介导差异生长. 这种信号转导机制在顶钩的凹 面(concave side)起作用, 包括生长素介导的TMK1的C端剪切. 细胞质和细胞核易位的 TMK1 C-端专一地与 Aux/IAA家族的两个非典型的转录抑制因子(IAA32和 IAA34)相互作用, 并磷酸化它们, 从而调控ARF转录因 子. 与典型生长素信号途径中Aux/IAA转录抑制因子的 降解相反, TMK1 C-端稳定非典型的IAA32和IAA34转 录抑制因子以调控基因表达, 最终抑制生长. 生长素TMK1信号转导途径起源于细胞表面, 被高水平的生长 素触发, 以及与TIR1/AFB信号转导途径共享部分重叠 的一组转录因子, 从而介导复杂的发育过程.

\section{IAA对种子休眠与萌发的调控}

种子的休眠与萌发被多种植物激素相互作用调控. 研究发现, 生长素以剂量依赖的方式调控种子的休眠 与萌发; 在种子萌发过程中, 生长素正调控ABA和负调 控GA的生物合成与信号转导途径 ${ }^{[12,13,131]}$.

\section{1 种子休眠依赖于生长素的水平}

在黑暗条件下, $1 \mu \mathrm{mol} / \mathrm{L}$ 外源IAA处理显著延缓大
豆(G. max cv. ND-12和C-103)种子的萌发进程 ${ }^{[13]}$. 种子 萌发的最初可见性状包括种皮破裂和胚根伸出 ${ }^{[1,2]}$. 外 源IAA处理延缓大豆 'ND-12’ 的种皮破裂和胚根伸出, 显著降低萌发种子的胚根长度和幼苗鲜重. IAA对 'ND-12'种子萌发的抑制作用是依赖浓度的，包括种皮 破裂、胚根伸出、种子萌发后的胚根长度和幼苗鲜重, 且随着IAA浓度的增加其抑制作用更为明显 ${ }^{[13]}$. 人工 合成的生长素如NAA和2,4-D对大豆种子的萌发也有 延迟作用，在相同浓度下，2,4-D的延迟作用大于 $\mathrm{NAA}^{[13]}$. 此外, 外源IAA也以剂量依赖的方式有效地增 加野生型拟南芥新鲜收获种子的休眠 ${ }^{[12]}$ 和烟草种子的 次生休眠 ${ }^{[131]}$. $4^{\circ} \mathrm{C}$ 下层积 $4 \mathrm{~d}$ 能够解除外源IAA对拟南 芥种子萌发的抑制作用 ${ }^{[12]}$. 层积和未层积拟南芥种子 的萌发速率被低浓度 $(0.05 \sim 5 \mathrm{nmol} / \mathrm{L})$ 的IAA和 $2,4-\mathrm{D}$ 促 进，被高浓度 $(0.05 \sim 5 \mu \mathrm{mol} / \mathrm{L})$ 的IAA和2,4-D抑制 ${ }^{[131]}$. 5 $\mathrm{nmol} / \mathrm{L}$ IAA处理增加拟南芥吸胀种子中肧根尖端生长 素报告基因DR5::GUS的信号，表明外源IAA处理能增 加内源生长素的反应水平 ${ }^{[132]}$.

过量产生生长素的转基因株系iaaM-OX种子的休 眠特性比野生型更强; ia $M M-O X$ 植株的新鲜收获的湿 (freshly harvested wet, FHW)种子在吸胀后 $30 \mathrm{~d}$ 不萌发, 而野生型植株的相同种子在吸胀后 $5 \mathrm{~d}$ 具有 $50 \%$ 萌发

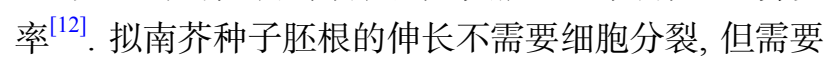
下胚轴-胚根过渡区的细胞伸长 ${ }^{[133]}$. 伸长区细胞体积的 增加伴随着 $4 \mathrm{C}$ 和内多倍体(endopolyploid, $8 \mathrm{C}$ 和 $16 \mathrm{C}$ )核 的比例增加 ${ }^{[134]}$. 流式细胞技术分析表明, 在 $5 \mathrm{nmol} / \mathrm{L}$ IAA或者 2,4-D存在下, 吸胀 24 和 $36 \mathrm{~h}$ 种子中肧细胞的 DNA含量以及 $4 \mathrm{C}$ 和 $8 \mathrm{C}$ 核的水平增加 ${ }^{[132]}$.

YUC黄素单加氧酶家族是生长素生物合成的关键 酶 ${ }^{[17,18]}$. YUC1、YUC2 和YUC6 在种子发育过程中表达, 在种子发育后期阶段达到峰值(http://www.bar.utoronto. ca/efp/cgi-bin/efpWeb.cgi). 由于yuc1 yuc2 yuc6三重突 变体表现出低的育性, yucl yuc6双突变体被用来研究 种子休眠特性的变化. 与野生型种子比较, 生长素缺陷 的yuc1 yuc 6双突变体的FHW种子表现出显著降低的休 眠特性, 但在 $4^{\circ} \mathrm{C}$ 层积 $4 \mathrm{~d}$ 后, 突变体与野生型种子之间 的萌发率没有差异 ${ }^{[12]}$, 表明种子休眠被生长素调控.

\section{2 生长素信号转导途径与种子休眠}

典型生长素信号转导途径包括由TIR1/AFB受体、 $\mathrm{Aux} / \mathrm{IAA}$ 转录抑制因子和ARF转录因子介导的级 联 ${ }^{[19,20]}$. 三重突变体 $t i r 1$ afb2 afb3 和四重突变体tirl afbl 
$a f b 2 a f b 3$ 种子都不能形成下胚轴和根分生组织, 可能是 因为在胚胎发生过程中需要生长素 ${ }^{[12]}$. tirl afb2 和tirl $a f b 3$ 双突变体的FHW种子像野生型种子一样能够正常 萌发 ${ }^{[12]}$. IAA 7/AXR2 和IAA17/AXR3 是两种由 TIR $1 /$ $\mathrm{AFB}$ 介导的生长素信号途径的转录抑制因子，突变体 axr 2-1 和 $\operatorname{axr} 3-1$ 表现出一种生长素反应基因的组成性 抑制, 它们的FHW种子也比野生型种子萌发更早 ${ }^{[12]}$.

MIR160(35S:MIR160)下调生长素信号转导途径中 3 个转录因子 $A R F 10 、 A R F 16$ 和 $A R F 17$ 的表达 ${ }^{[21,135]}$. 与 野生型种子比较, 过表达MIR160的转基因植株的FHW 种子表现出显著降低的休眠特性 ${ }^{[12]}$. 与 $35 S: M I R 160$ 转 基因植株的表型一致, arf10 arf16双突变体表现出显著 降低的种子休眠; 表达 $A R F 10$ 和 $A R F 16$ 的抗MIR160形 式(分别为 $m A R F 10$ 和 $m A R F 16$ )的 2 个转基因株系表现出 显著增加的种子休眠，表明MIR160通过下调生长素信 号转导来降低种子休眠 ${ }^{[12]}$. 这些结果都表明, 生长素信 号转导途径是种子休眠必需的，其中ARF 10 和ARF 16 作为关键的下游组分起作用.

LEC2(leafy cotyledon2)是一种B3结构域转录因子, 被认为是一个胚胎发生的中枢调节因子 ${ }^{[136]}$. 研究表明, $L E C 2$ 的诱导迅速活化拟南芥中 $Y U C 2$ 和 YUC4基因的表 达, 以及LEC2 能够直接与 $Y U C 4$ 的启动子结合 ${ }^{[136]}$. 除了 $Y U C 2$ 和YUC4外, LEC2也可能正调控拟南芥中的YUC1 和 $Y U C 10$ 基因 ${ }^{[137]}$, 尽管 $\mathrm{LEC} 2$ 是否直接与 $Y U C 1 、 Y U C 2$ 和YUC10的启动子结合还不清楚. SHI/STY(short internodes/stylish)家族成员作为转录因子起作用，以及调控 各种植物器官的发育 ${ }^{[138]}$. STY1基因的诱导也活化 $Y U C 4$ 的表达和导致拟南芥幼苗中IAA水平的增加 ${ }^{[138]}$. STY1蛋白能够直接与 $Y U C 4$ 启动子结合, 也可能正调控 $Y U C 8^{[138]}$. IDD(indeterminate domain)转录因子IDD14、 IDD15和IDD16在器官形态发生和向地性反应中起作 用 ${ }^{[139]}$ 。此外，TAAI 和 $Y U C 5$ 基因被鉴定为 IDD 14 和 IDD16的直接靶点. IDD 14的过表达增加拟南芥幼苗中 $T A A 1$ 和YUC5 的表达以及内源IAA的积累. PIF和碱性 螺旋-环-螺旋(basic helix-loop-helix, bHLH)转录因子在 光和高温介导的发育变化中起重要作用. PIF4和PIF5 与 $Y U C 8$ 的启动子结合以及PIF7与 $Y U C 8$ 和 $Y U C 9$ 的启动 子结合以增加IAA的生物合成. PIF4介导的TAA1 和 $Y U C 4$ 的活化也在拟南芥高温诱导的IAA生物合成和下 胚轴伸长中起作用 ${ }^{[57]}$. 此外, REVEILLE1 和 PLETHORA转录活化因子正调控拟南芥 $Y U C$ 基因 ${ }^{[140]}$ 相反, SPL/NZZ(sporocyteless/nozzle)转录因子是一种
孢子发生的调控因子，负调控 $Y U C 2$ 和 $Y U C 6$ 基因 ${ }^{[141]}$. 这些结果表明, 在发育和环境变化中 $T A A$ 和 $Y U C$ 基因家 族是植物中IAA水平调控的重要靶点.

\section{3 生长素正调控ABA生物合成和信号转导}

$\mathrm{ABA}$ 抑制大豆种子萌发，而 $\mathrm{GA}$ 促进大豆种子萌 发 ${ }^{[142]}$. qPCR 分析表明, IAA处理显著上调大豆种子吸 胀过程中 $\mathrm{ABA}$ 生物合成基因 $G m A B A 2$ 和 $G m A A O$ 的转录 水平, 其中 $G m A B A 2$ 在整个吸胀过程中保持较高的转录 水平, 而 $G m A A O$ 的转录水平在吸胀后 $3 \mathrm{~h}$ 达到峰值, 然 后下降; IAA处理显著降低ABA分解代谢基因 $G m C Y$ $P 707 A 1$ 的转录水平 ${ }^{[13]}$. 外源IAA处理通过上调 $G m A$ $B I 4 、 G m A B I 5$ 和 $G m R D 29-A$ 的转录水平显著增强 $\mathrm{ABA}$ 的信号转导, $G m A B I 4$ 和 $G m A B I 5$ 是ABA信号转导途径 中的关键正调控因子，而 $G m R D 29-A$ 是下游ABA反应 基因 ${ }^{[5]}$. 氟啶酮(fluridone)是一种ABA生物合成的抑制 剂, 氟啶酮处理促进大豆种子萌发, 增加萌发后胚根的 长度和幼苗鲜重, 并能恢复IAA处理种子的正常萌发表 型 $[13]$.

\subsection{1 生长素信号转导途径是ABA抑制种子萌发所需} $\mathrm{ABI} 4$ 和 $\mathrm{ABI} 5$ 是 2 个重要的转录因子，其功能缺失 突变体abi4和abi5-1对ABA介导的种子萌发抑制是不 敏感的，然而突变体的种子休眠没有变化 ${ }^{[7,8]}$ ，表明 $\mathrm{ABA} 介$ 导的种子休眠和ABA抑制种子萌发可能具有不 同的信号转导途径. 外源和内源IAA均以ABA依赖的 方式抑制种子萌发 ${ }^{[12]}$ ，表明生长素和ABA对种子萌发 具有协同抑制作用. 这种协同抑制作用是IAA剂量依 赖的, 在 $1 \mu \mathrm{mol} / \mathrm{L} \mathrm{ABA}$ 存在下, $4 \mu \mathrm{mol} / \mathrm{L}$ IAA的协同效 应最大；在缺乏ABA的情况下，相同浓度的IAA不抑制 种子萌发 ${ }^{[12]}$ ，表明生长素介导的种子萌发抑制依赖于 ABA.

在 $1 \mu \mathrm{mol} / \mathrm{L}$ ABA存在下, $y u c 1$ yuc 6 突变体种子的 萌发比野生型种子更快. 尽管 $t i r 1 a f b 1 a f b 2 a f b 3$ 的大多 数种子都有缺陷，但少数的四重突变体种子以及几乎 所有的单突变体和双突变体种子都是正常的，其萌发 类似于野生型种子. 四重突变体的正常种子对 $\mathrm{ABA}$ 不 敏感，生长素信号转导缺陷与 $\mathrm{ABA}$ 不敏感之间具有紧 密的正相关性. 此外, axr2-1和axr3-1突变体种子对 ABA的敏感性比野生型种子更低 ${ }^{[12]}$.

ARF活化/抑制下游生长素反应基因，在种子萌发 过程中, arf10和arf16对ABA的敏感性较低, arf10 arf16 双突变体对 $\mathrm{ABA}$ 的敏感性更低. 这一结果与 $35 \mathrm{~S}$ : 
MIR 160和 arf10 arf16的种子休眠特性一致. 表达 $M I R 160$ 抗性的 $m A R F 10$ 和 $m A R F 16$ 的作用与 $\operatorname{arfl0}$ 和 $\operatorname{arf16}$ 突变的作用相反 ${ }^{[12]}$.

\subsubsection{ABI3和生长素在种子休眠与萌发中的作用}

生长素在ABA介导的种子休眠与萌发过程中可能 有两种作用方式: 生长素促进 $\mathrm{ABA}$ 的生物合成, 或者活 化ABA反应. 由于IAA对种子休眠与萌发的影响存在 于 $\mathrm{ABA}$ 生物合成缺陷突变体 $a b a 2-1$ 中, 可以认为 $\mathrm{ABA}$ 的生物合成不是生长素在种子休眠与萌发中的作用位 点 $^{[12]}$.

$\mathrm{ABI} 3 、 \mathrm{ABI} 4$ 和 $\mathrm{ABI} 5$ 是 3 个种子专一的 $\mathrm{ABA}$ 信号转 导的关键组分, 然而, 只有 $\mathrm{ABI} 3$ 在 $\mathrm{ABA}$ 介导的种子休眠 和萌发抑制中起作用 ${ }^{[12]}$. 在野生型种子中, $A B I 3 \mathrm{mRNA}$ 的水平在未萌发的种子中较高, 在萌发后迅速下降; 相 反, 从iaaM-OX和 $m A R F 10$ 植株中新鲜收获的干(freshly harvested dry, FHD)种子在其吸胀过程中 $A B I 3$ mRNA 的水平保持较长的时间(直到 $108 \mathrm{~h}$ ), 但在 $\operatorname{arf10} \operatorname{arf16}$ 双 突变体种子中 $A B I 3 \mathrm{mRNA}$ 的水平比野生型种子下降更 快. 在ABA存在下, 类似的结果也在种子萌发过程中观 察到. 此外, 外源IAA也增加FHD种子吸胀过程中 $A B I 3$ mRNA的水平, 但对ABI3蛋白的稳定性具有很小的影 响 ${ }^{[12]}$. 这些结果表明, 生长素和ARF10/16对于吸胀后 种子中 $A B I 3$ 表达的维持是必需的.

Liu等人 ${ }^{[12]}$ 发现，在abi3-1突变体中IAA和ABA对 种子萌发的协同抑制作用丧失, ia $a M-O X$ 株系种子的 深休眠和ABA过敏性反应在iaaM-OX/abi3 双突变体中 降低, 在 $m A R F 16 / a b i 3$ 双突变体中也观察到种子的深休 眠和 $\mathrm{ABA}$ 敏感性下降, 以及生长素诱导萌发种子中 ABI5蛋白的大量积累，表明生长素对种子休眠的促进 作用和ABA对种子萌发的抑制作用依赖于 ABI3 的 功能.

\subsubsection{ARF间接地调控ABI3的表达}

$\mathrm{ARF}$ 通过与启动子中的AuxRE结合来调控一系列 生长素反应基因的表达 ${ }^{[19,20]}$. 利用野生型 $A B I 3: A B I 3$ 或 者突变的 $m A B I 3: A B I 3$ 来转化 abi3-1, 其中TGTCTC序列 被突变为AAGCTC; 突变的 $m A B I 3: A B I 3$ 结构与野生型 结构相同, 能够补充abi3-1 中ABA不敏感表型 ${ }^{[12]}$. 这一 结果表明, TGTCTC序列对于种子萌发过程中 $A B I 3$ 的 表达不是必需的. 这一假设与酵母单杂试验一致, 表明 $\mathrm{ARF} 10$ 和ARF16不与 $A B I 3$ 启动子中含有 TGTCTC元件 的DNA区域或者覆盖一个 $2.7 \mathrm{~kb} \mathrm{ABI} 3$ 启动子的其他区 域结合 ${ }^{[12]}$.
此外, $A B I 3$ 仅仅在吸胀和未萌发的种子中被 $\mathrm{ABA}$ 高度活化, 而在幼苗中不被ABA活化 ${ }^{[12]}$. 利用myc标记 的ARF16转基因株系的未萌发(吸胀后 $12 \mathrm{~h}$ )种子进行 染色质免疫沉淀(chromatin immunoprecipitation, ChIP) 分析, 试验结果与酵母单杂数据一致, 抗myc抗体不沉 淀 $A B I 3$ 启动子片段, 表明ARF10或者ARF16不可能直 接与 $A B I 3$ 启动子结合, 可能招募或者活化另外的种子 专一转录因子来促进 $A B I 3$ 的表达(图3).

\section{4 生长素负调控GA生物合成和信号转导}

在种子吸胀过程中, $G m G A 3 、 G m G A 3 o \times 2$ 、 $G m G A 30 x 1$ 和 $G m K A O$ 的表达水平被IAA处理明显降低, 特别是 $G m G A 3$ 的转录水平被IAA处理显著降低, 且从 吸胀后 $3 \mathrm{~h}$ 一直保持在很低的水平 ${ }^{[13]}$. IAA处理也降低 大豆种子吸胀过程中活性 $\mathrm{GA}_{1}$ 和 $\mathrm{GA}_{4}$ 的水平, 显著增加 $\mathrm{ABA}$ 的水平, 从而使 $\mathrm{GA}_{1} / \mathrm{ABA}$ 和 $\mathrm{GA}_{4} / \mathrm{ABA}$ 的比值下 调 ${ }^{[13]} ; \mathrm{GA} / \mathrm{ABA}$ 比值是种子萌发的关键因素 ${ }^{[4,5,143]}$. 多 效唑(paclobutrazol, PAC)是一种GA生物合成的抑制剂, 能延缓大豆种子萌发以及降低萌发后胚根的长度和幼 苗鲜重 ${ }^{[13]}$.

$G m R G L$ 编码DELLA转录调控蛋白, 抑制拟南芥种 子萌发过程中种皮的破裂 ${ }^{[144]}$. 在IAA存在下, $G m R G L$ 的转录水平在大豆种子吸胀过程中稍有上调 ${ }^{[13]}$. 这些 结果表明, 外源IAA处理似乎负调控种子萌发过程中 GA的生物合成和信号转导.

\section{4 结束语}

生长素是一种重要的植物激素, 在植物生长和发 育的许多生理生化过程中起关键作用，例如肧和果实 的发育、组织分化、根的起始、植物的向地性以及植 物对生物和非生物胁迫的反应 ${ }^{[17,130,145]}$. 尽管近年来这 些领域的研究已经取得了重要的进展, 但仍然有一些 重要的科学问题需要进一步研究. 例如生长素的生物 合成和分解代谢都存在多条途径 ${ }^{[17,18]}$, 那么这些途径 是否同时存在于同一物种的同一组织，还是具有物 种、组织和发育阶段的特异性? 在响应生长发育和环 境变化时, 为了控制组织或者细胞内的生长素水平, 这 些途径怎样被启动、运行和协调?

IAA信号转导途径包括典型和非典型的生长素信 号转导途径 ${ }^{[20,26]}$. 最近研究认为, 在非典型的生长素信 号转导途径中, 生长素也通过AUX1进人细胞, 被定位 于细胞核中的 $\mathrm{SCF}^{\mathrm{TIR} 1 / \mathrm{AFB}}$ 受体复合体和细胞质中的 




Auxin signaling activation

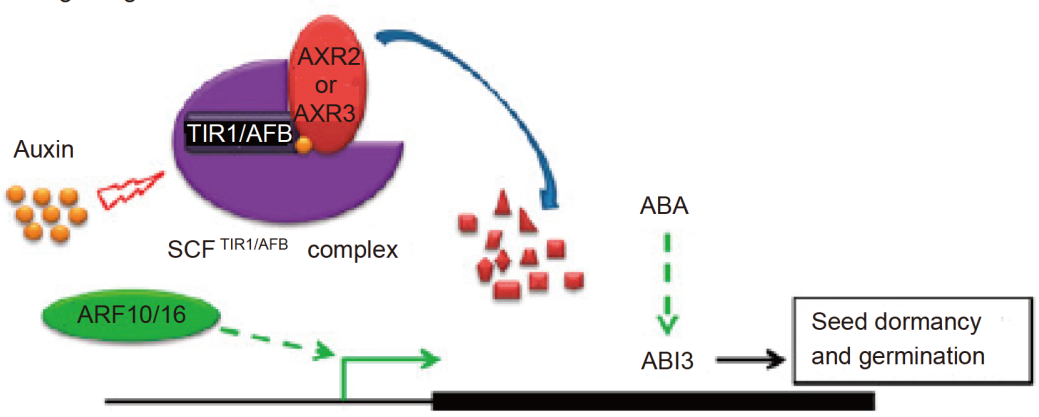

图 $3 \mathrm{ABA}$-生长素相互作用调控种子休眠/萌发的模型 ${ }^{[12]}$. 当生长素信号转导被低水平生长素或者信号中断失活时, 生长素反应因子 10 (ARF10)和ARF16被Aux/IAA抑制因子AXR2和AXR3失活. ABI3的表达不能被维持, 从而解除种子休眠. 随着生长素信号转导的活化, 生长素与 生长素受体TIR1/AFB F-box蛋白结合, 促进IAA7/AXR2和IAA17/AXR3的降解. 这种降解释放ARF10和ARF16的活性, 以及维持 $A B I 3$ 的表达, 从 而保持种子休眠和抑制种子萌发. 实心箭头表示直接调控, 虚线箭头表示间接调控. 黑色方框表示 $A B I 3$ 的基因区域

Figure 3 A model for seed dormancy/germination regulated by the ABA-auxin interaction ${ }^{[12]}$. When auxin signaling is inactivated by low auxin level or signaling disruption, ARF10 (auxin response factor 10) and ARF16 are inactivated by the Aux/IAA repressors AXR2 and AXR3. ABI3 expression cannot be maintained, and seed dormancy is released. With auxin signaling activation, auxin binds to the auxin receptor TIR1/AFB F-box proteins and promotes the degradation of IAA7/AXR2 and IAA17/AXR3. The degradation releases the activity of ARF10 and ARF16 and maintains the expression of $A B I 3$, which protects seed dormancy and inhibits seed germination. The solid arrows indicate direct regulation, and the dotted arrows indicate indirect regulation. The black box indicates the $A B I 3$ gene region

TIR1所感受. 值得研究的是, 在整合生理条件或者对环 境信号反应时哪一条途径优先响应，这2条途径之间怎 样联系还不清楚. 此外, 在非典型的生长素信号转导途 径中, 生长素转导的下游事件仍然不清楚 ${ }^{[26]}$.

生长素反应组织对变化的生长素浓度具有不同的 反应能力. 在植物基因组中, 信号转导途径的所有核心 组分都由多个同源成员组成. 每个组分的不同成员都 有其独特的生化特性，这些核心组分的不同成员之间 的相互作用可能产生一系列的反应结果. 细胞是否通 过调控不同组的基因来响应不同生长素浓度的变化仍 然是一个未解决的问题 ${ }^{[20]}$.

生长素诱导的酸生长模型(acid growth model induced by auxin)提出, 生长素活化质膜 $\mathrm{H}^{+}$-ATPase质子
泵, 泵质子 $\left(\mathrm{H}^{+}\right)$进人细胞壁基质, 导致细胞壁的酸化. 细 胞壁的酸化激活钾通道(potassium channel), 钾通道运 输 $\mathrm{K}^{+}$进人细胞质, 促进水分吸收和维持膨压. 酸性 $\mathrm{pH}$ 活 化细胞壁松驰蛋白(wall-loosening protein)和酶, 使细胞 壁不同多糖之间的连接松驰. 细胞壁松弛蛋白和酶引 起纤维素微纤丝(cellulose microfibril)的滑动和移动, 增加细胞壁的孔隙度，导致细胞壁的伸展性增加和细 胞迅速伸长 ${ }^{[146]}$. 研究发现, 种子完成萌发仅仅需要下 胚轴-胚根过渡区的细胞伸长, 不需要细胞分裂 ${ }^{[133,134]}$, 以及低浓度 $(0.05 \sim 5 \mathrm{nmol} / \mathrm{L})$ 的生长素促进种子萌 发 ${ }^{[132]}$. 低浓度生长素是否通过生长素诱导的酸生长模 型促进种子萌发需要进一步证实, 这一模型的证实也 可能有助于种子萌发机理的解释.

\section{参考文献}

1 Xu H H, Li N, Liu S J, et al. Research progress in seed germination and its control (in Chinese). Acta Agron Sin, 2014, 40: 1141-1156 [徐恒恒, 黎妮, 刘树君, 等. 种子萌发及其调控的研究进展. 作物学报, 2014, 40: 1141-1156]

2 Bewley J D, Bradford K J, Hilhorst H W M, et al. Physiology of Development, Germination and Dormancy. 3rd ed. New York: Springer, 2013

3 Nonogaki H. Seed dormancy and germination emerging mechanisms and new hypotheses. Front Plant Sci, 2014, e5: 233 
4 Finkelstein R, Reeves W, Ariizumi T, et al. Molecular aspects of seed dormancy. Annu Rev Plant Biol, 2008, 59: 387-415

5 Shu K, Liu X, Xie Q, et al. Two faces of one seed: Hormonal regulation of dormancy and germination. Mol Plant, 2016, 9: 34-45

6 Song S Q, Liu J, Xu H H, et al. ABA metabolism and signaling and their molecular mechanism regulating seed dormancy and germination (in Chinese). Sci Agric Sin, 2020, 53: 857-873 [宋松泉, 刘军, 徐恒恒, 等. 脱落酸代谢与信号传递及其调控种子休眠与萌发的分子机制. 中国 农业科学, 2020, 53: 857-873]

7 Hiroyuki N. Seed biology updates-Highlights and new discoveries in seed dormancy and germination research. Front Plant Sci, $2017,8: 524$

8 Hiroyuki N. Seed germination and dormancy: The classic story, new puzzles, and evolution. J Integr Plant Biol, 2019, 61: 541-563

9 Ito T, Okada K, Fukazawa J, et al. DELLA-dependent and -independent gibberellin signaling. Plant Signal Behav, 2018, 13: e1445933

10 Urbanova T, Leubner-Metzger G. Gibberellin and seed germination. In: Hedden P, Thomas S G, eds. Annual Plant Reviews. Vol. 49: The Gibberellins. Oxford: John Wiley \& Sons, 2016. 253-284

11 Yang L, Jiang Z, Liu S, et al. Interplay between REVEILLE1 and RGA-LIKE2 regulates seed dormancy and germination in Arabidopsis. New Phytol, 2019, doi: 10.1111/nph.16236

12 Liu X, Zhang H, Zhao Y, et al. Auxin controls seed dormancy through stimulation of abscisic acid signaling by inducing ARF-mediated ABI3 activation in Arabidopsis. Proc Natl Acad Sci USA, 2013, 110: 15485-15490

13 Shuai H, Meng Y, Luo X, et al. Exogenous auxin represses soybean seed germination through decreasing the gibberellin/abscisic acid (GA/ABA) ratio. Sci Rep, 2017, 7: 12620

14 Song S Q, Liu J, Xu H H, et al. Biosynthesis and signaling of ethylene and their regulation on seed germination and dormancy (in Chinese). Acta Agron Sin, 2019, 45: 969-981 [宋松泉, 刘军, 徐恒恒, 等. 乙烯的生物合成与信号及其对种子萌发和休眠的调控. 作物学报, 2019, 45: 969981]

15 Corbineau F, Xia Q, Bailly C, et al. Ethylene, a key factor in the regulation of seed dormancy. Front Plant Sci, 2014, 5: 539

16 Wang Y, Li L, Ye T, et al. Cytokinin antagonizes ABA suppression to seed germination of Arabidopsis by downregulating ABI5 expression. Plant J, 2011, 68: 249-261

17 Casanova-Sáez R, Voß U. Auxin metabolism controls developmental decisions in land plants. Trends Plant Sci, 2019, 24: 741-754

18 Kasahara H. Current aspects of auxin biosynthesis in plants. Biosci Biotech Biochem, 2016, 80: 34-42

19 Leyser O. Auxin signaling. Plant Physiol, 2018, 176: 465-479

20 Weijers D, Wagner D. Transcriptional responses to the auxin hormone. Annu Rev Plant Biol, 2016, 67: 539-574

21 Liu P P, Montgomery T A, Fahlgren N, et al. Repression of AUXIN RESPONSE FACTOR10 by microRNA160 is critical for seed germination and post-germination stages. Plant J, 2007, 52: 133-146

22 He J, Duan Y, Hua D, et al. DEXH box RNA helicase-mediated mitochondrial reactive oxygen species production in Arabidopsis mediates crosstalk between abscisic acid and auxin signaling. Plant Cell, 2012, 24: 1815-1833

23 Ogawa M, Hanada A, Yamauchi Y, et al. Gibberellin biosynthesis and response during Arabidopsis seed germination. Plant Cell, 2003, 15: 15911604

24 Thole J M, Beisner E R, Liu J, et al. Abscisic acid regulates root elongation through the activities of auxin and ethylene in Arabidopsis thaliana. G3, 2014, 4: 1259-1274

25 Carrera E, Holman T, Medhurst A, et al. Gene expression profiling reveals defined functions of the ATP-binding cassette transporter COMATOSE late in phase II of germination. Plant Physiol, 2007, 143: 1669-1679

26 Kubeš M, Napier R. Non-canonical auxin signalling: Fast and curious. J Exp Bot, 2019, 70: 2609-2614

27 Ma Q, Grones P, Robert S. Auxin signaling: A big question to be addressed by small molecules. J Exp Bot, 2018, 69: 313-328

28 Shirley N J, Aubert M K, Wilkinson L G, et al. Translating auxin responses into ovules, seeds and yield: Insight from Arabidopsis and the cereals. J Integr Plant Biol, 2019, 61: 310-336

29 Lam H K, McAdam S A M, McAdam E L, et al. Evidence that chlorinated auxin is restricted to the Fabaceae but not to the Fabeae. Plant Physiol, 2015, 168: 798-803

30 Maeda H, Dudareva N. The shikimate pathway and aromatic amino acid biosynthesis in plants. Annu Rev Plant Biol, 2012, 63: 73-105

31 Mashiguchi K, Tanaka K, Sakai T, et al. The main auxin biosynthesis pathway in Arabidopsis. Proc Natl Acad Sci USA, 2011, 108: 18512-18517

32 Stepanova A N, Yun J, Robles L M, et al. The Arabidopsis YUCCA1 flavin monooxygenase functions in the indole-3-pyruvic acid branch of auxin biosynthesis. Plant Cell, 2011, 23: 3961-3973

33 Zhao Y. Auxin biosynthesis. Arabidopsis Book, 2014, 12: e0173

34 Brumos J, Alonso J M, Stepanova A N. Genetic aspects of auxin biosynthesis and its regulation. Physiol Plant, 2014, 151: 3-12

35 Eklund D M, Ishizaki K, Flores-Sandoval E, et al. Auxin produced by the indole-3-pyruvic acid pathway regulates development and gemmae dormancy in the liverwort Marchantia polymorpha. Plant Cell, 2015, 27: 1650-1669

36 Sugawara S, Hishiyama S, Jikumaru Y, et al. Biochemical analyses of indole-3-acetaldoxime-dependent auxin biosynthesis in Arabidopsis. Proc 
Natl Acad Sci USA, 2009, 106: 5430-5435

37 Mano Y, Nemoto K. The pathway of auxin biosynthesis in plants. J Exp Bot, 2012, 63: 2853-2872

38 Stepanova A N, Robertson-Hoyt J, Yun J, et al. TAA1-mediated auxin biosynthesis is essential for hormone crosstalk and plant development. Cell, 2008, 133: 177-191

39 Yamada M, Greenham K, Prigge M J, et al. The TRANSPORT INHIBITOR RESPONSE2 gene is required for auxin synthesis and diverse aspects of plant development. Plant Physiol, 2009, 151: 168-179

40 Yoshikawa T, Ito M, Sumikura T, et al. The rice FISH BONE gene encodes a tryptophan aminotransferase, which affects pleiotropic auxin-related processes. Plant J, 2014, 78: 927-936

41 Chen Q, Dai X, De-Paoli H, et al. Auxin overproduction in shoots cannot rescue auxin deficiencies in Arabidopsis roots. Plant Cell Physiol, 2014, 55: 1072-1079

42 Cheng Y, Dai X, Zhao Y. Auxin biosynthesis by the YUCCA flavin monooxygenases controls the formation of floral organs and vascular tissues in Arabidopsis. Genes Dev, 2006, 20: 1790-1799

43 Novák O, Hényková E, Sairanen I, et al. Tissue-specific profiling of the Arabidopsis thaliana auxin metabolome. Plant J, 2012, 72: 523-536

44 Kriechbaumer V, Wang P, Hawes C, et al. Alternative splicing of the auxin biosynthesis gene YUCCA4 determines its subcellular compartmentation. Plant J, 2012, 70: 292-302

45 Dai X, Mashiguchi K, Chen Q, et al. The biochemical mechanism of auxin biosynthesis by an Arabidopsis YUCCA flavin-containing monooxygenase. J Biol Chem, 2013, 288: 1448-1457

46 Cheng Y, Dai X, Zhao Y. Auxin synthesized by the YUCCA flavin monooxygenases is essential for embryogenesis and leaf formation in Arabidopsis. Plant Cell, 2007, 19: 2430-2439

47 Hentrich M, Böttcher C, Düchting P, et al. The jasmonic acid signaling pathway is linked to auxin homeostasis through the modulation of YUCCA8 and YUCCA9 gene expression. Plant J, 2013, 74: 626-637

48 Fujino K, Matsuda Y, Ozawa K, et al. NARROW LEAF 7 controls leaf shape mediated by auxin in rice. Mol Genet Genomics, 2008, 279: 499-507

49 Bernardi J, Lanubile A, Li Q B, et al. Impaired auxin biosynthesis in the defective endosperm 18 mutant is due to mutational loss of expression in the ZmYucl gene encoding endosperm-specific YUCCA1 protein in maize. Plant Physiol, 2012, 160: 1318-1328

$50 \mathrm{He} \mathrm{W}$, Brumos J, Li H, et al. A small-molecule screen identifies 1-kynurenine as a competitive inhibitor of TAA1/TAR activity in ethylenedirected auxin biosynthesis and root growth in Arabidopsis. Plant Cell, 2011, 23: 3944-3960

51 Nishimura T, Hayashi K, Suzuki H, et al. Yucasin is a potent inhibitor of YUCCA, a key enzyme in auxin biosynthesis. Plant J, 2014, 77: 352-366

52 Soeno K, Goda H, Ishii T, et al. Auxin biosynthesis inhibitors, identified by a genomics-based approach, provide insights into auxin biosynthesis. Plant Cell Physiol, 2010, 51: 524-536

53 Zheng Z, Guo Y, Novák O, et al. Coordination of auxin and ethylene biosynthesis by the aminotransferase VAS1. Nat Chem Biol, 2013, 9: 244246

54 Kong W, Li Y, Zhang M, et al. A novel Arabidopsis microRNA promotes IAA biosynthesis via the indole-3-acetaldoxime pathway by suppressing SUPERROOT1. Plant Cell Physiol, 2015, 56: 715-726

55 Bender J, Celenza J L. Indolic glucosinolates at the crossroads of tryptophan metabolism. Phytochem Rev, 2009, 8: 25-37

56 Douglas Grubb C, Zipp B J, Ludwig-Müller J, et al. Arabidopsis glucosyltransferase UGT74B1 functions in glucosinolate biosynthesis and auxin homeostasis. Plant J, 2004, 40: 893-908

57 Franklin K A, Lee S H, Patel D, et al. Phytochrome-interacting factor 4 (PIF4) regulates auxin biosynthesis at high temperature. Proc Natl Acad Sci USA, 2011, 108: 20231-20235

58 Kriechbaumer V, Park W J, Piotrowski M, et al. Maize nitrilases have a dual role in auxin homeostasis and $\beta$-cyanoalanine hydrolysis. J Exp Bot, 2007, 58: 4225-4233

$59 \mathrm{Su}$ T, Xu J, Li Y, et al. Glutathione-indole-3-acetonitrile is required for camalexin biosynthesis in Arabidopsis thaliana. Plant Cell, 2011, 23: 364 380

60 Zhao Y. Trp-dependent auxin biosynthesis in Arabidopsis: Involvement of cytochrome P450s CYP79B2 and CYP79B3. Genes Dev, 2002, 16: $3100-3112$

61 Irmisch S, Zeltner P, Handrick V, et al. The maize cytochrome P450 CYP79A61 produces phenylacetaldoxime and indole-3-acetaldoxime in heterologous systems and might contribute to plant defense and auxin formation. BMC Plant Biol, 2015, 15: 128

62 Korasick D A, Enders T A, Strader L C. Auxin biosynthesis and storage forms. J Exp Bot, 2013, 64: 2541-2555

63 Nemoto K, Hara M, Suzuki M, et al. The NtAMI1 gene functions in cell division of tobacco BY-2 cells in the presence of indole-3-acetamide. FEBS Lett, 2009, 583: 487-492

64 Woodward A W. Auxin: Regulation, action, and interaction. Ann Bot, 2005, 95: 707-735

65 Quittenden L J, Davies N W, Smith J A, et al. Auxin biosynthesis in pea: Characterization of the tryptamine pathway. Plant Physiol, 2009, 151: 
$1130-1138$

66 Yu P, Lor P, Ludwig-Müller J, et al. Quantitative evaluation of IAA conjugate pools in Arabidopsis thaliana. Planta, 2015, 241: 539-548

67 Wang B, Chu J, Yu T, et al. Tryptophan-independent auxin biosynthesis contributes to early embryogenesis in Arabidopsis. Proc Natl Acad Sci USA, 2015, 112: 4821-4826

68 Ludwig-Müller J. Auxin conjugates: Their role for plant development and in the evolution of land plants. J Exp Bot, 2011, 62: 1757-1773

69 Staswick P E, Serban B, Rowe M, et al. Characterization of an Arabidopsis enzyme family that conjugates amino acids to indole-3-acetic acid. Plant Cell, 2005, 17: 616-627

70 Porco S, Pěnčík A, Rashed A, et al. Dioxygenase-encoding AtDAO1 gene controls IAA oxidation and homeostasis in Arabidopsis. Proc Natl Acad Sci USA, 2016, 113: 11016-11021

71 Zheng Z, Guo Y, Novák O, et al. Local auxin metabolism regulates environment-induced hypocotyl elongation. Nat Plants, 2016, 2: 16025

72 Gutierrez L, Mongelard G, Floková K, et al. Auxin controls Arabidopsis adventitious root initiation by regulating jasmonic acid homeostasis. Plant Cell, 2012, 24: 2515-2527

73 Westfall C S, Sherp A M, Zubieta C, et al. Arabidopsis thaliana GH3.5 acyl acid amido synthetase mediates metabolic crosstalk in auxin and salicylic acid homeostasis. Proc Natl Acad Sci USA, 2016, 113: 13917-13922

74 Rampey R A, LeClere S, Kowalczyk M, et al. A family of auxin-conjugate hydrolases that contributes to free indole-3-acetic acid levels during Arabidopsis germination. Plant Physiol, 2004, 135: 978-988

75 Jakubowska A. The auxin conjugate 1-O-indole-3-acetyl- $\beta$-D-glucose is synthesized in immature legume seeds by IAGlc synthase and may be used for modification of some high molecular weight compounds. J Exp Bot, 2004, 55: 791-801

76 Jakubowska A, Kowalczyk S. A specific enzyme hydrolyzing 6-O(4-O)-indole-3-ylacetyl- $\beta$-d-glucose in immature kernels of Zea mays. J Plant Physiol, 2005, 162: 207-213

77 Ishimaru K, Hirotsu N, Madoka Y, et al. Loss of function of the IAA-glucose hydrolase gene TGW6 enhances rice grain weight and increases yield. Nat Genet, 2013, 45: 707-711

78 Qin G, Gu H, Zhao Y, et al. An indole-3-acetic acid carboxyl methyltransferase regulates Arabidopsis leaf development. Plant Cell, 2005, 17: 2693-2704

79 Abbas M, Hernández-García J, Pollmann S, et al. Auxin methylation is required for differential growth in Arabidopsis. Proc Natl Acad Sci USA, 2018, 115: 6864-6869

80 Yang Y, Xu R, Ma C, et al. Inactive methyl indole-3-acetic acid ester can be hydrolyzed and activated by several esterases belonging to the AtMES esterase family of Arabidopsis. Plant Physiol, 2008, 147: 1034-1045

81 Strader L C, Culler A H, Cohen J D, et al. Conversion of endogenous indole-3-butyric acid to indole-3-acetic acid drives cell expansion in Arabidopsis seedlings. Plant Physiol, 2010, 153: 1577-1586

82 Frick E M, Strader L C. Roles for IBA-derived auxin in plant development. J Exp Bot, 2018, 69: 169-177

83 Pěnčík A, Simonovik B, Petersson S V, et al. Regulation of auxin homeostasis and gradients in Arabidopsis roots through the formation of the indole-3-acetic acid catabolite 2-oxindole-3-acetic acid. Plant Cell, 2013, 25: 3858-3870

84 Kubeš M, Yang H, Richter G L, et al. The Arabidopsis concentration-dependent influx/efflux transporter ABCB4 regulates cellular auxin levels in the root epidermis. Plant J, 2012, 69: 640-654

85 Zhao Z, Zhang Y, Liu X, et al. A role for a dioxygenase in auxin metabolism and reproductive development in rice. Dev Cell, 2013, 27: 113-122

86 Tanaka K, Hayashi K, Natsume M, et al. UGT74D1 catalyzes the glucosylation of 2-oxindole-3-acetic acid in the auxin metabolic pathway in Arabidopsis. Plant Cell Physiol, 2014, 55: 218-228

87 Mellor N, Band L R, Pěnčík A, et al. Dynamic regulation of auxin oxidase and conjugating enzymes AtDAO1 and GH3 modulates auxin homeostasis. Proc Natl Acad Sci USA, 2016, 113: 11022-11027

88 Dharmasiri N, Dharmasiri S, Estelle M. The F-box protein TIR1 is an auxin receptor. Nature, 2005, 435: 441-445

89 Parry G, Calderon-Villalobos L I, Prigge M, et al. Complex regulation of the TIR1/AFB family of auxin receptors. Proc Natl Acad Sci USA, 2009, 106: $22540-22545$

90 Gilkerson J, Hu J, Brown J, et al. Isolation and characterization of cul1-7, a recessive allele of CULLIN1 that disrupts SCF function at the C terminus of CUL1 in Arabidopsis thaliana. Genetics, 2009, 181: 945-963

91 Calderón Villalobos L I A, Lee S, De Oliveira C, et al. A combinatorial TIR1/AFB-Aux/IAA co-receptor system for differential sensing of auxin. Nat Chem Biol, 2012, 8: 477-485

92 Tan X, Calderon-Villalobos L I A, Sharon M, et al. Mechanism of auxin perception by the TIR1 ubiquitin ligase. Nature, 2007, 446: 640-645

93 Salehin M, Bagchi R, Estelle M. SCF ${ }^{\mathrm{TIR} 1 / \mathrm{AFB}}$-based auxin perception: Mechanism and Role in plant growth and development. Plant Cell, 2015, 27: 9-19

94 Yu H, Zhang Y, Moss B L, et al. Untethering the TIR1 auxin receptor from the SCF complex increases its stability and inhibits auxin response. 
Nat Plants, 2015, 1: 14030

95 Yamaguchi N, Wu M F, Winter C M, et al. A molecular framework for auxin-mediated initiation of flower primordia. Dev Cell, 2013, 24: 271282

96 Guilfoyle T J. The PB1 domain in auxin response factor and Aux/IAA proteins: A versatile protein interaction module in the auxin response. Plant Cell, 2015, 27: 33-43

97 Korasick D A, Westfall C S, Lee S G, et al. Molecular basis for AUXIN RESPONSE FACTOR protein interaction and the control of auxin response repression. Proc Natl Acad Sci USA, 2014, 111: 5427-5432

98 Dreher K A, Brown J, Saw R E, et al. The Arabidopsis Aux/IAA protein family has diversified in degradation and auxin responsiveness. Plant Cell, 2006, 18: 699-714

99 Moss B L, Mao H, Guseman J M, et al. Rate motifs tune auxin/indole-3-acetic acid degradation dynamics. Plant Physiol, 2015, 169: 803-813

100 Causier B, Ashworth M, Guo W, et al. The TOPLESS interactome: A framework for gene repression in Arabidopsis. Plant Physiol, 2012, 158: 423-438

$101 \mathrm{Ke} \mathrm{J,} \mathrm{Ma} \mathrm{H,} \mathrm{Gu} \mathrm{X,} \mathrm{et} \mathrm{al.} \mathrm{Structural} \mathrm{basis} \mathrm{for} \mathrm{recognition} \mathrm{of} \mathrm{diverse} \mathrm{transcriptional} \mathrm{repressors} \mathrm{by} \mathrm{the} \mathrm{TOPLESS} \mathrm{family} \mathrm{of} \mathrm{corepressors.} \mathrm{Sci} \mathrm{Adv,}$ 2015, 1: e1500107

102 dos Santos Maraschin F, Memelink J, Offringa R. Auxin-induced, SCF ${ }^{\text {TIR1 }}$-mediated poly-ubiquitination marks AUX/IAA proteins for degradation. Plant J, 2009, 59: 100-109

103 Gilkerson J, Kelley D R, Tam R, et al. Lysine residues are not required for proteasome-mediated proteolysis of the auxin/indole acidic acid protein IAA1. Plant Physiol, 2015, 168: 708-720

104 Boer D R, Freire-Rios A, van den Berg W A M, et al. Structural basis for DNA binding specificity by the auxin-dependent ARF transcription factors. Cell, 2014, 156: 577-589

105 Finet C, Berne-Dedieu A, Scutt C P, et al. Evolution of the ARF gene family in land plants: Old domains, new tricks. Mol Biol Evol, 2013, 30: $45-56$

106 Kato H, Ishizaki K, Kouno M, et al. Auxin-mediated transcriptional system with aminimal set of components is critical formorphogenesis through the life cycle in Marchantia polymorpha. PLoS Genet, 2015, 11: e1005084

107 Nanao M H, Vinos-Poyo T, Brunoud G, et al. Structural basis for oligomerization of auxin transcriptional regulators. Nat Commun, 2014 , 5: 3617

108 Piya S, Shrestha S K, Binder B, et al. Protein-protein interaction and gene co-expression maps of ARFs and Aux/IAAs in Arabidopsis. Front Plant Sci, 2014, 5: 744

109 Richter R, Behringer C, Zourelidou M, et al. Convergence of auxin and gibberellin signaling on the regulation of the GATA transcription factors GNC and GNL in Arabidopsis thaliana. Proc Natl Acad Sci USA, 2013, 110: 13192-13197

110 Wang S, Hagen G, Guilfoyle T J. ARF-Aux/IAA interactions through domain III/IV are not strictly required for auxin-responsive gene expression. Plant Signal Behav, 2013, 8: e24526

111 Wu M F, Yamaguchi N, Xiao J, et al. Auxin-regulated chromatin switch directs acquisition of flower primordium founder fate. eLife, 2015, 4: e09269

112 Krogan N T, Hogan K, Long J A. APETALA2 negatively regulates multiple floral organ identity genes in Arabidopsis by recruiting the corepressor TOPLESS and the histone deacetylase HDA19. Development, 2012, 139: 4180-4190

113 Clapier C R, Cairns B R. The biology of chromatin remodeling complexes. Annu Rev Biochem, 2009, 78: 273-304

114 Hertel R, Thomson K S, Russo V E A. In-vitro auxin binding to particulate cell fractions from corn coleoptiles. Planta, 1972, 107: 325-340

115 Enders T A, Strader L C. Auxin activity: Past, present, and future. Am J Bot, 2015, 102: 180-196

116 Gao Y, Zhang Y, Zhang D, et al. Auxin binding protein 1 (ABP1) is not required for either auxin signaling or Arabidopsis development. Proc Natl Acad Sci USA, 2015, 112: 2275-2280

117 Badescu G O, Napier R M. Receptors for auxin: Will it all end in TIRs? Trends Plant Sci, 2006, 11: 217-223

118 Fendrych M, Akhmanova M, Merrin J, et al. Rapid and reversible root growth inhibition by TIR1 auxin signalling. Nat Plants, 2018, 4: 453-459

119 Dindas J, Scherzer S, Roelfsema M R G, et al. AUX1-mediated root hair auxin influx governs SCFTIR1/AFB-type $\mathrm{Ca}^{2+}$ signaling. Nat Commun, 2018, 9: 1174

120 Wang R, Zhang Y, Kieffer M, et al. HSP90 regulates temperature-dependent seedling growth in Arabidopsis by stabilizing the auxin co-receptor F-box protein TIR1. Nat Commun, 2016, 7: 10269

121 Uchida N, Takahashi K, Iwasaki R, et al. Chemical hijacking of auxin signaling with an engineered auxin-TIR1 pair. Nat Chem Biol, 2018, 14: 299-305

122 Roosjen M, Paque S, Weijers D. Auxin response factors: Output control in auxin biology. J Exp Bot, 2018, 69: 179-188

123 Simonini S, Deb J, Moubayidin L, et al. A noncanonical auxin-sensing mechanism is required for organ morphogenesis in Arabidopsis. Genes Dev, 2016, 30: 2286-2296 
124 Simonini S, Mas P J, Mas C M V S, et al. Auxin sensing is a property of an unstructured domain in the auxin response factor ETTIN of Arabidopsis thaliana. Sci Rep, 2018, 8: 13563

125 Simonini S, Stephenson P, Østergaard L. A molecular framework controlling style morphology in Brassicaceae. Development, 2018, 145: $\operatorname{dev} 158105$

126 Mutte S K, Kato H, Rothfels C, et al. Origin and evolution of the nuclear auxin response system. eLife, 2018, 7: e33399

127 Marhava P, Bassukas A E L, Zourelidou M, et al. A molecular rheostat adjusts auxin flux to promote root protophloem differentiation. Nature, 2018, 558: 297-300

128 Enders T A, Frick E M, Strader L C. An Arabidopsis kinase cascade influences auxin-responsive cell expansion. Plant J, 2017, 92: 68-81

129 Dai N, Wang W, Patterson S E, et al. The TMK subfamily of receptor-like kinases in Arabidopsis display an essential role in growth and a reduced sensitivity to auxin. PLoS One, 2013, 8: e60990

130 Li Z, Zhang J, Liu Y, et al. Exogenous auxin regulates multi-metabolic network and embryo development, controlling seed secondary dormancy and germination in Nicotiana tabacum L. BMC Plant Biol, 2016, 16: 41

131 Wang Z, Chen F, Li X, et al. Arabidopsis seed germination speed is controlled by SNL histone deacetylase-binding factor-mediated regulation of AUX1. Nat Commun, 2016, 7: 13412

132 Finch-Savage W E, Leubner-Metzger G. Seed dormancy and the control of germination. New Phytol, 2006, 171: 501-523

133 Sliwinska E, Bassel G W, Bewley J D. Germination of Arabidopsis thaliana seeds is not completed as a result of elongation of the radicle but of the adjacent transition zone and lower hypocotyl. J Exp Bot, 2009, 60: 3587-3594

134 Wang J W, Wang L J, Mao Y B, et al. Control of root cap formation by microRNA-targeted auxin response factors in Arabidopsis. Plant Cell, 2005, 17: 2204-2216

135 Stone S L, Braybrook S A, Paula S L, et al. Arabidopsis LEAFY COTYLEDON2 induces maturation traits and auxin activity: Implications for somatic embryogenesis. Proc Natl Acad Sci USA, 2008, 105: 3151-3156

136 Wójcikowska B, Jaskóła K, Gąsiorek P, et al. LEAFY COTYLEDON2 (LEC2) promotes embryogenic induction in somatic tissues of Arabidopsis, via YUCCA-mediated auxin biosynthesis. Planta, 2013, 238: 425-440

137 Eklund D M, Ståldal V, Valsecchi I, et al. The Arabidopsis thaliana STYLISH1 protein acts as a transcriptional activator regulating auxin biosynthesis. Plant Cell, 2010, 22: 349-363

138 Cui D, Zhao J, Jing Y, et al. The Arabidopsis IDD14, IDD15, and IDD16 cooperatively regulate lateral organ morphogenesis and gravitropism by promoting auxin biosynthesis and transport. PLoS Genet, 2013, 9: e1003759

139 Pinon V, Prasad K, Grigg S P, et al. Local auxin biosynthesis regulation by PLETHORA transcription factors controls phyllotaxis in Arabidopsis. Proc Natl Acad Sci USA, 2013, 110: 1107-1112

140 Li L C, Qin G J, Tsuge T, et al. SPOROCYTELESS modulates YUCCA expression to regulate the development of lateral organs in Arabidopsis. New Phytol, 2008, 179: 751-764

141 Meng Y, Chen F, Shuai H W, et al. Karrikins delay soybean seed germination by mediating abscisic acid and gibberellin biogenesis under shaded conditions. Sci Rep, 2016, 6: 22073

142 Shu K, Chen Q, Wu Y, et al. ABI4 mediates antagonistic effects of abscisic acid and gibberellins at transcript and protein levels. Plant J, 2016, 85: 348-361

143 Piskurewicz U, Lopez-Molina L. The GA-signaling repressor RGL3 represses testa rupture in response to changes in GA and ABA levels. Plant Signal Behav, 2009, 4: 63-65

144 Cai Z, Zeng D, Liao J, et al. Genome-wide analysis of auxin receptor family genes in Brassica juncea var. tumida. Genes, 2019, 10: 165

145 Majda M, Robert S. The role of auxin in cell wall expansion. Int J Mol Sci, 2018, 19: 951 


\title{
Metabolism and signaling of auxins and their roles in regulating seed dormancy and germination
}

\author{
Songquan Song ${ }^{1,2^{*}}$, Jun Liu ${ }^{2}$, Cuifang Tang ${ }^{3}$, Wenhu Zhang ${ }^{2}$, Hengheng $\mathrm{Xu}^{2}$, Qi Zhang ${ }^{2} \&$ \\ Jiadong $\mathrm{Gao}^{2}$ \\ ${ }^{1}$ Institute of Botany, Chinese Academy of Sciences, Beijing 100093, China; \\ ${ }^{2}$ Guangdong Provincial Key Lab for Crop Germplasm Resources Preservation and Utilization/Agro-Biological Gene Research Center, Guangdong \\ Academy of Agricultural Sciences, Guangzhou 510640, China; \\ ${ }^{3}$ Shenzhen Qianhai Guoken Earth Fund Management Co., Ltd, Guangzhou 510630, China \\ * Corresponding author, E-mail: sqsong@ibcas.ac.cn
}

During germination, a quiescent seed is converted to a seedling with high metabolic activity by germination, which is a critical step in the life cycle of seed plants. Seed germination is a complex process co-regulated by genetic and environmental factors, of which phytohormone regulation may be a highly conserved mechanism in seed plants. Auxin is one of the most important signaling molecules in plants, and it controls all aspects of plant growth and development, including morphogenesis and responses to environmental changes. Auxin is biosynthesized, stored and inactivated by many parallel pathways, and it is also perceived and transduced by canonical and non-canonical pathways. The role of auxin is mainly regulated by its biosynthesis and catabolism, as well as by a signaling pathway during seed dormancy and germination. Here, we mainly summarize research progress on metabolism and signaling of auxin and its roles in regulating seed dormancy and germination. Tryptophan (Trp) is a common precursor of indole-3-acetic acid (IAA) in plants, and IAA is biosynthesized from Trp by the indole-3-pyruvate (IPA), indole-3-acetaldoxime (IAOx), indole-3-acetaldoxime (IAM) and tryptamine (TAM) pathways, of which the IPA pathway is a main one. The IAOx pathway may be species-specific in Brassicaceae, and it plays an auxiliary role in IAA biosynthesis in Arabidopsis. However, present evidence is insufficient to propose the IAM and TAM pathways as major routes to IAA biosynthesis in plants. The majority of cellular IAA is inactivated by conjugation to amino acids, peptides, proteins and sugars to produce the transient storage forms, or by irreversible catabolic degradation. Heretofore, oxidative attenuation of IAA through formation of 2-oxindole-3-acetic acid (oxIAA) and subsequent conjugation to glucose was considered the major pathway for IAA inactivation. IAA signaling pathways include canonical and non-canonical auxin signaling pathways. In the canonical auxin signaling pathway, auxin binds to the F-box proteins of the TRANSPORT INHIBITION RESISTANT1/AUXIN SIGNALING F-BOX (TIR1/AFB) and AUXIN/INDOLE-3-ACETIC ACID (Aux/IAA) transcriptional repressor families. Then, the SCF ${ }^{\text {TIR1/AFB }}$ E3 ubiquitin ligase complex transfers activated ubiquitin to Aux/IAA. The polyubiquitination of Aux/IAA results in its degradation in $26 \mathrm{~S}$ proteasome, thereby releasing repression of the AUXIN RESPONSEFACTORs (ARFs) and activating transcription of auxin induced genes. The non-canonical auxin signaling pathway mainly includes pathways mediated by TIR1, ETTIN and receptor-like kinases; however, the events downstream from auxin binding remain unknown. Auxin regulates seed dormancy and germination in a dose-dependent manner. During seed germination, auxin positively regulates ABA and negatively regulates GA biosynthesis and signaling pathways. Finally, we propose some scientific issues that need to be investigated in the future. There are multiple pathways for biosynthesis and catabolism of auxin. Do these pathways exist in the same tissue of the same species at the same time, or do species, tissues and developmental stages have specific pathways? How are these pathways activated, operated and coordinated in response to growth and development and environmental changes to control auxin levels in tissues or cells? Auxin signaling includes canonical and non-canonical pathways. Which pathways respond preferentially in integrating physiological conditions or in responding to environmental signals, and what is the relationship between them? In the plant genome, the core components of signaling pathways are composed of multiple homologous members, and each member has its specific biochemical characteristics. Does the combination of different members of these core components produce similar reaction results? Do low concentrations of auxin promote seed germination via the auxin induced acid growth model? This paper provides a basis for further investigation of the molecular mechanism regulating seed dormancy and germination by auxin.

auxin, dormancy, germination, metabolism, seed, signaling

doi: 10.1360/TB-2020-0509 